\title{
Evaluation of the protective role of exogenous growth regulators against Ni toxicity in woody shrub Daphne jasminea
}

\author{
Alina Wiszniewska ${ }^{1} \cdot$ Ewa Muszyńska $^{2} \cdot$ Ewa Hanus-Fajerska $^{1} \cdot$ Kinga Dziurka $^{3} \cdot$ Michał Dziurka $^{3}$
}

Received: 9 May 2018 / Accepted: 8 August 2018 / Published online: 16 August 2018

(c) The Author(s) 2018

\begin{abstract}
Main conclusion The results provide a significant verification of the activity of exogenously applied phytohormones: gibberellic acid, jasmonic acid, and brassinolide in the modulation of the plant's response to nickel treatment.
\end{abstract}

\begin{abstract}
The study investigated nickel accumulation and its toxicity to Daphne jasminea shoots cultured in vitro with or without exogenous supplementation with phytohormones: gibberellic acid (GA3), jasmonic acid (JA), and brassinolide (BL). The aim was to verify the modulatory effect of exogenous plant growth regulators (PGRs) on plant reaction to Ni excess. The combined action of $\mathrm{Ni}$ and PGRs was evaluated at the anatomical, ultrastructural, and biochemical levels. Nickel toxicity was manifested in decreased biomass accretion and growth tolerance index (83-53.6\%), attributed to enhanced synthesis of growth inhibitors, mainly abscisic acid. As a defence reaction, endogenous gibberellins accumulated. Exogenous GA3 ameliorated the plant reaction to $\mathrm{Ni}$ stress, inducing proliferation and growth rate. Ni tolerance in the presence of GA3 was attributed to peroxisomal reactions that stimulated the synthesis of endogenous JA. In contrast, the application of BL caused enhanced $\mathrm{Ni}$ accumulation. Plants suffered from pronounced stress due to massive oxidation. The defence strategy of plants subjected to Ni and BL involved cell wall rearrangements. Exogenous JA stimulated the synthesis of active auxins and salicylic acid, contributing to enhanced mitotic activity within explants. However, JA disturbed the integrity of chloroplasts and lamellar compartments. Our study revealed that an action of exogenous PGRs may either enhance tolerance to Ni or increase metal toxicity in $D$. jasminea. Particularly in in vitro culture, where explants are subjected to external phytohormonal stimuli, the combined effects of supplemental PGRs may enhance stress and substantially affect plant development. Our results provide a significant verification of exogenous PGRs activity in the modulation of plant response to nickel.
\end{abstract}

Keywords Brassinolide $\cdot$ Gibberellins $\cdot$ Heavy metal $\cdot$ Jasmonic acid $\cdot$ Phytohormones $\cdot$ TEM analysis

Electronic supplementary material The online version of this article (https://doi.org/10.1007/s00425-018-2979-6) contains supplementary material, which is available to authorized users.

Alina Wiszniewska

a.wiszniewska@ogr.ur.krakow.pl

1 Unit of Botany and Plant Physiology, Institute of Plant Biology and Biotechnology, Faculty of Biotechnology and Horticulture, University of Agriculture in Kraków, Al. 29 Listopada 54, 31-425 Kraków, Poland

2 Department of Botany, Faculty of Agriculture and Biology, Warsaw University of Life Sciences (SGGW),

Nowoursynowska 159, Building 37, 02-776 Warsaw, Poland

3 The Franciszek Górski Institute of Plant Physiology, Polish Academy of Sciences, Niezapominajek 21, 30-239 Kraków, Poland

\author{
Abbreviations \\ BL Brassinolide \\ PGRs Plant growth regulators \\ sPGRs Supplemental plant growth regulators \\ JA Jasmonic acid \\ GA3 Gibberellic acid \\ ROS Reactive oxygen species \\ TEM Transmission electron microscopy
}

\section{Introduction}

Nickel (Ni) is a trace metal that, in low concentrations, is essential to plants. Usually, its content in plant tissues ranges from 0.01 to $10 \mu \mathrm{g} / \mathrm{g}$ DW (Seregin and Kozhevnikova 2006; Chen et al. 2009). This element is a constituent of several plant metalloenzymes, including ureases, a few superoxide 
dismutases, glyoxalases, and hydrogenases (Boer et al. 2014; Fabiano et al. 2015). In recent years, the accumulation of $\mathrm{Ni}$ in environment increased due to anthropogenic activities; thus far, more often plants suffer from excess of $\mathrm{Ni}$ rather than from its deficiency (Yusuf et al. 2011). Nickel excess is toxic to the majority of plant species, and it causes growth retardation as a result of versatile metabolic disturbances, such as oxidative stress, osmotic and nutrient imbalance, chlorosis and related photosynthesis inhibition, as well as decreased enzymatic activity (Pietrini et al. 2015; Matraszek et al. 2016; Gupta et al. 2017). In natural sites, Ni occurs in high concentrations in ultramafic (serpentine) soils, where local flora developed unique adaptations to cope with elevated level of $\mathrm{Ni}$, resulting in increased tolerance and/or hyperaccumulation. Several species of woody shrubs belonging to the genus Daphne, such as D. mucronata, D. gnidium, and D. alpina, exhibit tolerance to high concentrations of nickel (Ater et al. 2000; Bani et al. 2013; Muhammad et al. 2013). Another Daphne species, D. jasminea, was found to exhibit in vitro tolerance to $\mathrm{Pb}$ and $\mathrm{Cd}$ (Wiszniewska et al. 2015, 2017a, b). These premises indicate the considerable potential of Daphne species to develop stable tolerance against heavy metal toxicity.

Increasing soil pollution with heavy metals forces us to search for effective technologies of soil clean-up, as well as strategies to minimize stress reactions in plants grown in polluted soil (Asgher et al. 2015; Wiszniewska et al. 2016). The latter includes the use of phytohormones and regulatory compounds to increase plant tolerance against heavy metal toxicity (Gangwar et al. 2014). In the case of hyperaccumulating plants, exogenous supplementation with PGRs may facilitate heavy metal accumulation in plant tissues due to enhanced growth and biomass accretion. This, in turn, can accelerate heavy metal removal from the soil via phytoextraction (Cabello-Conejo et al. 2013, 2014; Bulak et al. 2014). In non-hyperaccumulating species, exogenous treatment with PGRs can enhance defence reactions, allowing the restoration of normal growth and development in stressful conditions (Siddiqui et al. 2011; Piotrowska-Niczyporuk et al. 2012).

Plant growth regulators are active components of a signal cascade related to the induction of a plant stress response (Singh et al. 2016). Abiotic stress causes alarming changes in the level of endogenous phytohormones, resulting in growth inhibition to minimize injuries. The usual reaction is a decrease in the concentration of cytokinins, auxins, and gibberellins, and an increase in the content of ABA, jasmonates, and salicylic acid (Atici et al. 2005; Bajguz and Hayat 2009; Bücker-Neto et al. 2017). Other regulatory compounds, such as brassinosteroids, polyamines, peptides, organic acids, and oligosaccharides, also play a role in plant stress response, acting as immunomodulators (Meng et al. 2009; Bajguz 2011; Asgher et al. 2015). It was reported that exogenous application of various PGRs increases plant survival in the presence of heavy metals, mainly by counteracting biomass decrease, enhancing photosynthesis and stimulating antioxidant activity (Saeidi-sar et al. 2007; Piotrowska-Niczyporuk et al. 2012; Gemrotová et al. 2013; Han et al. 2016; Kaur et al. 2018). At the physiological level, these processes are regulated by endogenous phytohormones. In turn, concentrations of these compounds are affected by stress and external hormonal treatment. However, information concerning the effect of exogenously applied PGRs on the profile of endogenous phytohormones in plants suffering from heavy metal stress is still incomplete. There is a little attention given to the fact that supplemental stimuli with PGRs may itself deregulate hormonal balance, contributing to the enhancement of the stress reaction of plants treated with heavy metals.

Therefore, the aim of our study was to assess the level of nickel toxicity to Daphne jasminea shoots cultured in vitro in the absence or presence of supplemental PGRs (sPGRs), i.e., gibberellic acid (GA3), jasmonic acid (JA), and brassinolide (BL), and to verify the modulatory effect of exogenous PGRs on plant reactions to Ni excess. We exploited well established, proliferating shoot cultures of a woody plant species to create a model system in which both nickel toxicity and protective role of exogenous PGRs could be verified and evaluated. We hypothesized the following: (1) the presence of $\mathrm{Ni}$ induces stress that leads to structural and metabolic rearrangements in plant functioning; (2) the application of different exogenous PGRs affects both the profile of endogenous phytohormones and nickel accumulation, contributing to either the enhancement or suppression of the defence reaction. We evaluated the combined action of $\mathrm{Ni}$ and PGRs at the level of organ anatomy and ultrastructure, and biochemical parameters, including targeted profiling of selected endogenous phytohormones, photosynthetic pigments, phenolic compounds, and antioxidant activity. We also compared the effect of sPGRs on Ni accumulation.

\section{Materials and methods}

\section{Plant cultures}

Stock cultures of Daphne jasminea (Sibth. \& Sm.) shoots were multiplicated on modified WPM medium (Lloyd and McCown 1980) containing $12.3 \mu \mathrm{M}$ N6-[2-isopentyl]adenine (2iP) and $5.37 \mu \mathrm{M}$ 1-naphthaleneacetic acid (NAA), as described previously (Wiszniewska et al. 2017a, b).

Test cultures were established using $5 \mathrm{~mm}$-long explants. In the first part of an experiment, microcuttings grew on the basal media supplemented with nickel sulfate in concentrations of $0.05,0.1,0.5$, and $1.0 \mathrm{mM} \mathrm{NiSO}_{4}$. The control 
medium did not contain nickel sulfate and was referred further as $\mathrm{Ni}(-)$.

Initially, all sPGRs were pre-tested in concentration of $10 \mu \mathrm{M}$. However, in the case of JA and BL, such a high concentration was found to be extremely inhibitory to explants, which virtually did not grow and died within 2 weeks of culture (preliminary study, data not shown). Therefore, in the main experiment, $0.5 \mu \mathrm{M} \mathrm{JA}$ and $0.2 \mu \mathrm{M}$ BL were applied, corresponding to a concentration of $0.1 \mathrm{mg} / \mathrm{L}$. In contrast, GA3 applied in concentrations of $0.1 \mathrm{mg} / \mathrm{L}$ and $1.0 \mathrm{mg} / \mathrm{L}$ did not influence the growth of $D$. jasminea microcuttings (preliminary study, not shown), and therefore, $10 \mu \mathrm{M} \mathrm{GA3}$ (approx. $3.4 \mathrm{mg} / \mathrm{L}$ ) was tested in the main experiment (according to the literature survey).

In the main experiment, the basal medium containing $0.05 \mathrm{mM} \mathrm{NiSO}_{4}$ was enriched with one sPGR: $10 \mu \mathrm{M}$ GA3 (Sigma); $0.5 \mu \mathrm{M}$ JA (Sigma), and 0.2 $\mu \mathrm{M}$ BL (Sigma). The control medium without sPGRs contained $0.05 \mathrm{mM}$ $\mathrm{NiSO}_{4}$ and was referred further as $\mathrm{Ni}(+)$. The $\mathrm{pH}$ of the medium was adjusted to 5.6. Nickel sulfate was added to the medium prior to autoclaving at $121{ }^{\circ} \mathrm{C}, 0.1 \mathrm{MPa}$ for $15 \mathrm{~min}$ to avoid alterations in medium $\mathrm{pH}$. All sPGR solutions were filter sterilized using syringe filter (millipore) and added to the warm medium after autoclaving, prior to medium solidification.

Ten microcuttings per $250 \mathrm{~mL}$ Erlenmeyer flask were explanted on the respective media. Cultures were maintained for 8 weeks in a growth chamber at $22{ }^{\circ} \mathrm{C}$, under $16 \mathrm{~h}$ photoperiod (irradiance $80 \mu \mathrm{mol} \mathrm{m} \mathrm{s}^{-2}$ ). Cool white fluorescent lamps were used as a light source.

\section{Growth response and Ni accumulation}

After 8 weeks of culture, the obtained shoots were counted and the micropropagation coefficient (MC) was calculated using the formula:

$\mathrm{MC}=$ (number of induced adventitious shoots /total number of explants).

Plant organs were measured and weighted. For dry matter determination, samples were dried at $105^{\circ} \mathrm{C}$ in an oven for $24 \mathrm{~h}$ and weighted afterwards. Rooting efficiency was expressed as rooting percentage on the basis of number of rooted explants.

Growth tolerance index (GTI, in \%) was calculated on the basis of DW of plant organs (either shoots or roots), using the formula:

GTI $=$ (mean DW of organ developed on supplemented medium /mean DW of organ developed on control medium) $\times 100$.

Plant material for $\mathrm{Ni}$ accumulation analysis was washed with distilled water, dried for $24 \mathrm{~h}$ in $105^{\circ} \mathrm{C}$, and mineralized in suprapure $\mathrm{HNO}_{3}$ (Merck) in a microwave oven. Inductively coupled plasma-mass spectrometry (ICP-MS)
(Elan 6100, Perkin Elmer) was applied to determine the $\mathrm{Ni}$ content in the entire plantlets.

\section{Anatomy and ultrastructure}

Plant samples were fixed according to Karnovsky (1965), and subsequently post-fixed in $2 \% \mathrm{OsO}_{4}$ for $2 \mathrm{~h}$ at $4{ }^{\circ} \mathrm{C}$, dehydrated in an ethanol series, substituted by propylene oxide and embedded in glycidyl ether 100 epoxy resin (Serva) equivalent to the former Epon812. The resin polymerization was performed at $65{ }^{\circ} \mathrm{C}$ for $24 \mathrm{~h}$. Semi-thin sections were prepared using Jung RM 2065 microtome, and stained with methylene blue and azure A prior to examination under a light microscope (Olympus-Provis). Ultra-thin sections were prepared with Ultracut UCT Leica microtome, stained with uranyl acetate and lead citrate, and examined under a transmission electron microscope (Morgagni 268D).

\section{Biochemical analyses}

\section{Targeted profiling of endogenous phytohormones}

Targeted profiling of endogenous phytohormones was conducted based on method by Dziurka et al. (2016). Plant material was lyophilized and pulverized. To exactly weighted samples of about $10 \mathrm{mg}$ stable isotope labelled internal standards (ISTD), mixture was added. Samples were triple extracted with $1 \mathrm{~mL}$ of methanol/water/formic acid buffer ( $\mathrm{MeOH} / \mathrm{H}_{2} \mathrm{O} / \mathrm{HCOOH} 15 / 4 / 1$, by vol.) at ambient temperature. After centrifugation ( $3 \mathrm{~min}, 22,000 \mathrm{~g}$, at $15^{\circ} \mathrm{C}$ ), clear supernatants were joined and evaporated under $\mathrm{N}_{2}$. Residue was suspended in 5\% $\mathrm{MeOH}$ in $1 \mathrm{M} \mathrm{HCOOH}$, cleaned up on hybrid SPE cartridges (BondElutPlexaPCX, AgilentTechnologies, Santa Clara, CA, USA) and processed as described by Hura et al. (2017). Phytohormones (auxins, cytokinins, gibberellins, abscisic acid, jasmonates, and salicylic acid) were analyzed by ultrahigh-performance liquid chromatography (UHPLC) using an Agilent Infinity 1260 coupled to 6410 Triple Quad LC/MS with ESI (electrospray interface) ion source (Agilent Technologies). Separation was achieved on AscentisExpress RP-Amide analytical column $(2.7 \mu \mathrm{m}$, $2.1 \mathrm{~mm}, 150 \mathrm{~mm}$; Supelco, Sigma-Aldrich) at linear gradient of $\mathrm{H}_{2} \mathrm{O}$ vs. acetonitrile with $0.01 \%$ of $\mathrm{HCOOH}$, both. Multiple reactions monitoring (MRM) transitions were used for the identification and quantification of all compounds of interest (Supplementary data, Table S1). MassHunter software was used to control the LC-MS/MS system and in data analysis. For MRM parameter optimization, MassHunter Optimizer was used. Internal standard recoveries were used to compensate phytohormone losses occurring at all the stages of analysis. Quantification was based on fivepoint calibration curves for all standards. 


\section{Photosynthetic pigments and phenolic compounds}

The content of photosynthetic pigments: total chlorophylls (sum of chlorophyll $a$ and chlorophyll $b$ ) and carotenoids in the plant material was determined according to Wellburn (1994) and expressed as $\mathrm{mg} / \mathrm{g} \mathrm{FW}$ of the sample.

Phenolic compounds (total phenols, phenylpropanoids, flavonols, and anthocyanins) were determined using UV/ Vis spectrophotometry (Fukumoto and Mazza 2000). Chlorogenic acid (CGA), caffeic acid (CA), and quercetin (QC) were used as standards for total phenolic content (TPC), phenylpropanoids, and flavonols, respectively. Anthocyanin content was expressed as cyanidin (CY), according to its molar extinction. Plant tissue $(0.1 \mathrm{~g})$ was ground with $5 \mathrm{~cm}^{3}$ of $80 \%$ methanol and centrifuged for $15 \mathrm{~min}$ at $3000 \mathrm{~g}$. Supernatant was used for the analysis. The plant extract $(0.25 \mathrm{~mL})$ was mixed with $0.25 \mathrm{~mL} 0.1 \% \mathrm{HCl}$ (in $96 \%$ ethanol) and $4.50 \mathrm{~mL} 2 \% \mathrm{HCl}$ (in water), and after $15 \mathrm{~min}$, the absorbances at 280,320,360, and $520 \mathrm{~nm}$ were read (Hitachi U-2900 spectrophotometer). The content of phenolic compounds was expressed in $\mathrm{mg}$ of the respective standard equivalents per $100 \mathrm{~g} \mathrm{FW}$.

\section{Antioxidant activity}

Stable free radical DPPH (2,2-diphenyl-1-picrylhydrazyl) was used to test radical scavenging activity of $D$. jasminea plantlets (Pekkarinen et al. 1999). The changes in absorbance of DPPH solution, following reduction of DPPH, were measured at $517 \mathrm{~nm}$ at the moment of extract addition and after 30 min, using a Hitachi U-2900 spectrophotometer. For the analysis, $80 \%$ methanol extracts were used. The antioxidant activity of extracts was expressed in $\%$ of reduced $\mathrm{DPPH} \cdot$ radical by a unit of plant extract.

\section{Statistical analyses}

The experiments were conducted three times (three replicates), with minimum 30 explants (microcuttings) per treatment within one replicate. Data were subjected to ANOVA analysis (Statistica 10.0, StatSoft, Tulsa, OK, USA) and a post hoc Tukey's test was used to study differences between treatments at $P<0.05$.

\section{Results}

\section{Growth inhibition of $\mathrm{D}$. jasminea under increasing $\mathrm{Ni}$ doses}

This part of the study was designed to choose a non-lethal dose of $\mathrm{Ni}$ that exerts a toxic effect on cultured plants but allows growth and organogenic response during long-time culturing. As expected, with increasing nickel concentrations, the growth of $D$. jasminea microshoots was gradually inhibited. Application of $\mathrm{NiSO}_{4}$ in low doses, i.e., $0.05 \mathrm{mM}$ and $0.1 \mathrm{mM}$, slightly reduced shoot proliferation, as well as fresh and dry biomass accretion (Table 1). Moreover, in comparison with control treatment without $\mathrm{Ni}$, the growth tolerance index (GTI) decreased to $83-81 \%$, respectively. The micropropagation coefficient (MC) calculated after 8 weeks of culture reached 3.3 for $0.05 \mathrm{mM}$ and 2.7 for $0.1 \mathrm{mM}$ (differences statistically insignificant, $P>0.05$ ), in contrast to 4.1 in the absence of $\mathrm{Ni}(P<0.05)$ (Table 1). Shoots developed on $0.1 \mathrm{mM}$ and higher concentrations of $\mathrm{NiSO}_{4}$ became chlorotic. In the presence of $\mathrm{Ni}$, rooting efficiency also decreased from $70.3 \%$ (control) to 57.3 and $53.6 \%$ in 0.05 and $0.1 \mathrm{mM} \mathrm{NiSO}_{4}$, respectively. Higher doses of $\mathrm{Ni}$, i.e., 0.5 and $1.0 \mathrm{mM} \mathrm{NiSO}_{4}$, suppressed rhizogenesis completely. In these treatments, shoots did not proliferate $(\mathrm{MC}=1)$ and elongate, and GTI reached only $48-41 \%$ (Table 1).

\section{The effect of supplemental PGRs on growth and nickel accumulation}

On the basis of preliminary screening of the Ni dose (exhibiting relatively the lowest toxicity), in the main experiment,

Table 1 Growth parameters of Daphne jasminea microplantlets after 8 weeks of culture in the presence of various concentration of nickel sulfate

\begin{tabular}{|c|c|c|c|c|c|c|c|}
\hline $\begin{array}{l}\text { Nickel sul- } \\
\text { fate }(\mathrm{mM})\end{array}$ & $\mathrm{MC}$ & Shoot length (mm) & Shoot fresh weight (mg) & $\begin{array}{l}\text { Shoot dry } \\
\text { biomass (mg) }\end{array}$ & GTI $(\%)$ & Rooted shoots (\%) & $\begin{array}{l}\text { Root dry } \\
\text { biomass } \\
\text { (mg) }\end{array}$ \\
\hline 0 & $4.1 \mathrm{a}$ & $16.5 \pm 0.7 \mathrm{a}$ & $134 \pm 16 a$ & $16 \pm 1.2 \mathrm{a}$ & $\mathrm{n} / \mathrm{a}$ & $70.3 \mathrm{a}$ & $7 \pm 1.3 \mathrm{a}$ \\
\hline 0.05 & $3.3 b$ & $14.1 \pm 2.4 \mathrm{a}$ & $125 \pm 6 a b$ & $13 \pm 1.1 b$ & $83.4 \mathrm{a}$ & 57.3.b & $6 \pm 0.4 a$ \\
\hline 0.1 & $2.7 \mathrm{~b}$ & $12.1 \pm 2.2 b$ & $111 \pm 0.024 b$ & $13 \pm 1.2 b$ & $81.7 \mathrm{a}$ & $53.6 \mathrm{~b}$ & $6 \pm 2.1 \mathrm{a}$ \\
\hline 0.5 & $1.0 \mathrm{~b}$ & $11.2 \pm 1.6 \mathrm{bc}$ & $32 \pm 13 c$ & $6 \pm 0.7 \mathrm{c}$ & $48.4 b$ & $0 \mathrm{c}$ & - \\
\hline 1.0 & $1.0 \mathrm{~b}$ & $10.8 \pm 1.9 \mathrm{c}$ & $34 \pm 9 c$ & $5 \pm 1.6 \mathrm{c}$ & $41.7 b$ & $0 \mathrm{c}$ & - \\
\hline
\end{tabular}

$M C$ micropropagation coefficient, GTI growth tolerance index

Values are means of three replicates $\pm \mathrm{SD}$; means indicated by the same letter within the columns do not significantly differ at $P<0.05$ according to Tukey's test 
Table 2 Growth parameters of Daphne jasminea microplantlets after 8 weeks of culture on media containing nickel sulfate and supplemental PGRs (sPGRs)

\begin{tabular}{|c|c|c|c|c|c|c|}
\hline \multicolumn{2}{|l|}{ Treatment } & \multirow[t]{2}{*}{$\mathrm{MC}$} & \multirow[t]{2}{*}{ Shoot length (mm) } & \multirow{2}{*}{$\begin{array}{l}\text { Shoot dry } \\
\text { biomass } \\
(\mathrm{mg})\end{array}$} & \multirow[t]{2}{*}{ Rooted shoots (\%) } & \multirow{2}{*}{$\begin{array}{l}\text { Root dry } \\
\text { biomass } \\
\text { (mg) }\end{array}$} \\
\hline $\begin{array}{l}\text { Nickel sul- } \\
\text { fate }(\mathrm{mM})\end{array}$ & $\operatorname{sPGR}(\mu \mathrm{M})$ & & & & & \\
\hline 0 & 0 & $4.1 \mathrm{~A}$ & $16.5 \pm 0.7 \mathrm{~A}$ & $16 \pm 1.2 \mathrm{~A}$ & $70.3 \mathrm{~A}$ & $7 \pm 1.3 \mathrm{~A}$ \\
\hline 0.05 & 0 & $3.3 \mathrm{~B}$ & $14.1 \pm 2.4 \mathrm{Ab}$ & $13 \pm 1.1 \mathrm{~B}$ & $57.3 \mathrm{~B}$ & $6 \pm 0.4 \mathrm{~A}$ \\
\hline 0.05 & 0 & $3.3 \mathrm{~d}$ & $14.1 \pm 2.4 b$ & $13 \pm 1.1 b c$ & $57.3 \mathrm{a}$ & $6 \pm 0.4 b$ \\
\hline 0.05 & GA3 10 & $6.4 \mathrm{a}$ & $20.7 \pm 1.8 \mathrm{a}$ & $21 \pm 2.0 \mathrm{a}$ & $33.6 \mathrm{c}$ & $4 \pm 0.7 \mathrm{c}$ \\
\hline 0.05 & JA 0.5 & $5.7 \mathrm{~b}$ & $17.2 \pm 2.2 \mathrm{ab}$ & $16 \pm 0.8 b$ & $11.1 \mathrm{~d}$ & $4 \pm 0.4 c$ \\
\hline 0.05 & BL 0.2 & $4.9 \mathrm{c}$ & $8.9 \pm 1.3 c$ & $9 \pm 2.2 c$ & $10.2 \mathrm{~d}$ & $8 \pm 1.1 \mathrm{a}$ \\
\hline
\end{tabular}

Statistical significance of means for $\mathrm{Ni}(-)$ and $\mathrm{Ni}(+)$ control cultures is marked with capital letters, while that for $\mathrm{Ni}(+)$ cultures without and with sPGRs is marked with lowercase letters

$M C$ micropropagation coefficient, $G A$ gibberellic acid, $J A$ jasmonic acid, $B L$ brassinolide

Values are means of three replicates; for each organ, means indicated by the same letter within the columns do not significantly differ at $P<0.05$ according to Tukey's test

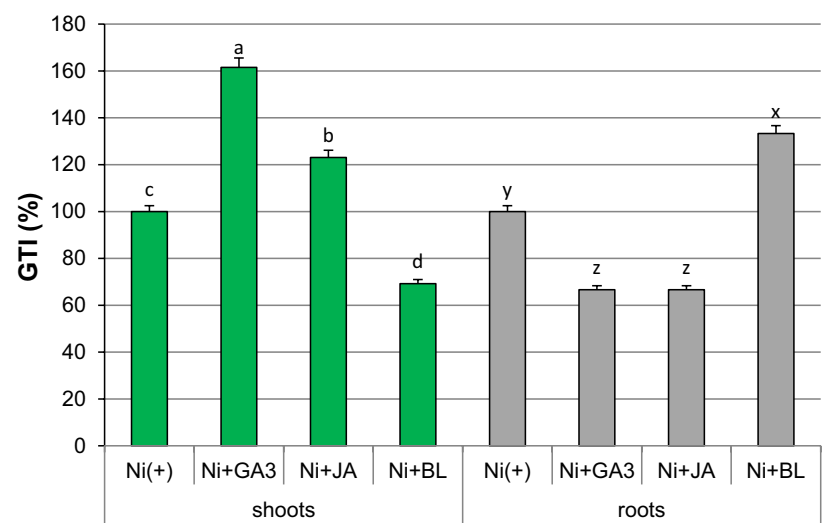

Fig. 1 Influence of supplemental PGRs on growth tolerance index (GTI) in Daphne jasminea shoots and roots treated with nickel sulfate. Different letters ( $\mathrm{a}-\mathrm{d}$ for shoots; $\mathrm{x}-\mathrm{z}$ for roots) indicate statistical significance of means $(n=3)$

cultures were established on the media containing either $0.05 \mathrm{mM} \mathrm{NiSO}_{4}$ alone (control treatment), or in a combination with one of the tested sPGRs. Exogenous sPGRs differentially affected growth responses to Ni ions. A substantial increase in shoot biomass in $\mathrm{Ni}(+)$ cultures occurred under supplementation with GA3 and JA, where GTI for shoots amounted to 161.5 and $123.1 \%$, respectively (Table 2; Fig. 1). GA3 particularly stimulated shoot elongation and proliferation, increasing the micropropagation coefficient (MC) to 6.4 (Table 2). The addition of BL slightly enhanced shoot proliferation $(\mathrm{MC}=4.9)$ in comparison with $\mathrm{Ni}(+)$ control culture $(\mathrm{MC}=3.3)$; however, shoot elongation was not improved, and biomass accretion decreased $(\mathrm{GTI}=69 \%)$ (Table 2; Fig. 1).

Rhizogenesis, which had been inhibited by Ni in comparison with untreated control shoots (Table 2), was further suppressed in the presence of sPGRs. Rooting

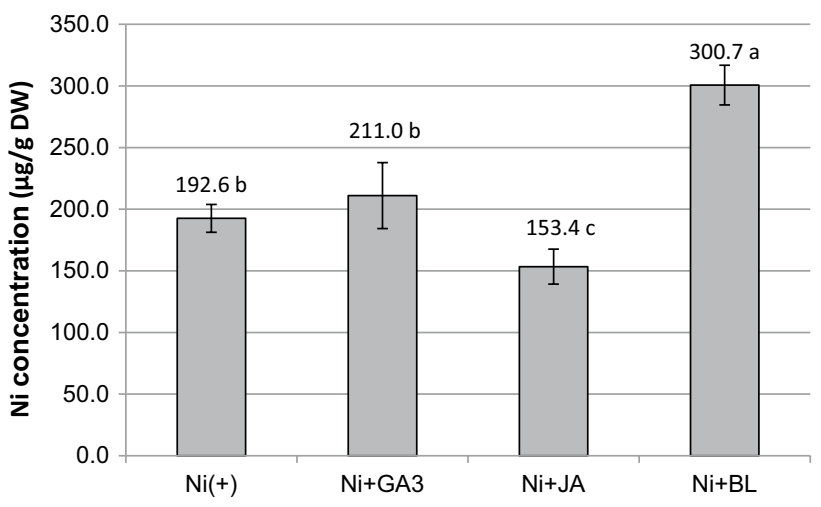

Fig. 2 Nickel concentration in D. jasminea shoots treated with $\mathrm{Ni}$ and supplemental phytohormones

efficiency declined significantly in all the sPGR treatments to $33.6 \%$ in $\mathrm{Ni}+\mathrm{GA} 3$, and only $11.1-10.2 \%$ in $\mathrm{Ni}+\mathrm{JA}$ and $\mathrm{Ni}+\mathrm{BL}$, respectively. Interestingly, in $\mathrm{Ni}+\mathrm{BL}$-treated cultures, the biomass of adventitious roots increased, and GTI reached the highest value of $133.3 \%$ (Table 2; Fig. 1). In $\mathrm{Ni}+\mathrm{GA} 3$ and $\mathrm{Ni}+\mathrm{JA}$ cultures, root biomass decreased, and GTI amounted to $61-65 \%$ (Fig. 1).

Shoots cultured without nickel $(\mathrm{Ni}(-))$ contained on average $1.7 \mu \mathrm{g}$ Ni per $1 \mathrm{~g} \mathrm{DW}$ (data not shown). During culturing in the presence of $0.05 \mathrm{mM} \mathrm{NiSO}_{4}$, shoots accumulated considerable amounts of $\mathrm{Ni}$ ions, and sPGRs differentially affected this process (Fig. 2). Ni content in $\mathrm{Ni}(+)$ shoots amounted to $192.6 \mu \mathrm{g} / \mathrm{g}$ DW. The application of BL increased Ni accumulation to $300.7 \mu \mathrm{g} / \mathrm{g} \mathrm{DW}$, while the application of JA reduced it to $153.4 \mu \mathrm{g} / \mathrm{g}$ DW $(P<0.05)$. GA3 had no influence on $\mathrm{Ni}$ accumulation, which had a concentration in $\mathrm{Ni}+\mathrm{GA} 3$ shoots $(211.0 \mu \mathrm{g} / \mathrm{g}$ DW) that was similar to those from $\mathrm{Ni}(+)$ control without sPGRs $(P>0.05)$ (Fig. 2). 


\section{Structural response}

Evaluation of structural response to Ni and sPGRs treatments was conducted on two distinct organs: (1) shoot bases, which were constantly in contact with culture medium and could be, therefore, directly affected, and (2) leaves, in which potential alterations were results of indirect action of nickel and SPGRs.

Anatomical examination of shoot bases and leaves: Nickel inhibited an organogenic response of cultured explants. The main differences noted between $\mathrm{Ni}(-)$ and $\mathrm{Ni}(+)$ cultures were delayed differentiation of adventitious shoots, and reduced formation of adventitious roots under $\mathrm{Ni}$ exposure. Microplantlets grown without $\mathrm{Ni}$ formed adventitious roots internally from the cambial ring (Fig. 3a), while, in all $\mathrm{Ni}(+)$ treatments, adventitious roots developed from callus. External cell layers of stems subjected to $\mathrm{Ni}(+)$ were disarranged (Fig. 3b, c). Supplemental PGRs affected pattern of organogenic events occurring in the shoot bases. In the presence of GA3 and BL, the formation of adventitious shoots was observed within shoot bases, originating from the cambial ring of the explant stem (Fig. 3d, f). In the presence of JA, stem tissues at the level of shoot base lost their integrity due to dedifferentiation into numerous small division centres (Fig. 3e).

In the leaves of all $\mathrm{Ni}(+)$-treated shoots (including these subjected to sPGRs), palisade parenchyma was less developed than in control $\mathrm{Ni}(-)$ leaves (Fig. 3g-1). Especially, in the presence of GA3, the mesophyll was composed mainly of spongy parenchyma. Epidermal cells accumulated a dark substance, presumably phenolics, and this phenomenon was intensified in the presence of JA and BL. In these two cases, phenolic-like compounds were also accumulated in the mesophyll (palisade parenchyma zone) (Fig. 3k, l). In turn, the application of GA3 almost completely suppressed accumulation of phenolics-like compounds in leaf blades (Fig. 3j).

Ultrastructure of shoot bases and leaves: cells of the shoot base in control $\mathrm{Ni}(-)$ treatment had a thick layer of cytoplasm rich in mitochondria, endoplasmatic reticulum, and other organelles (Fig. 4a-c). Under Ni exposure, disturbances in cell ultrastructure occurred. Most of Ni-treated cells had disintegrated cytoplasm with microvesicles and deformed chloroplasts (Fig. 4d-f). In the cells with wellpreserved cytoplasm, numerous ER and Golgi apparatus appeared (Fig. 4f). Within cell walls, granular deposits were accumulated (Fig. 4f). In contrast to $\mathrm{Ni}(+)$, in $\mathrm{Ni}+$ sPGRs, damaged cells were present mostly in the external part of the stem. In cells treated with $\mathrm{Ni}+\mathrm{JA}$ and $\mathrm{Ni}+\mathrm{BL}$, microscopic channels with granular deposits were formed in the cell walls (Fig. 4g, h). In the inner layers of sPGR-treated shoots, cell degeneration was less advanced (Fig. 4i). Disturbances included intensified vacuolation and the formation of multilamellar bodies inside the vacuoles (Fig. 4j, k). Furthermore, independently of the position within the shoot base, cells treated with $\mathrm{Ni}+\mathrm{JA}$ and $\mathrm{Ni}+\mathrm{BL}$ were surrounded by pectinlike substances and lipid droplets (Fig. 4k, 1).

Cells of leaves from control $\mathrm{Ni}(-)$ medium were typically arranged, with normally formed plastids, mitochondria, endoplasmic reticulum, Golgi apparatus, peroxisomes, and vacuoles with smooth tonoplast (Fig. 5a-c). Chloroplasts had a regular structure with numerous grana and plastoglobuli in spongy parenchyma or with a few small starch grains in palisade cells (Fig. 5b). In turn, leaf cells of all $\mathrm{Ni}(+)$-treated shoots accumulated starch grains and protein deposits in the external layer of the palisade parenchyma (Fig. 5d-f). In addition, in palisade cells of leaves treated with $\mathrm{Ni}(+)$ alone, $\mathrm{Ni}+\mathrm{JA}$ electron-dense deposits of phenolic-like compounds were formed either on the tonoplast or within the cytoplasm (Fig. 5d, f, g, k). In cells from sPGRs treatments, irrespectively of the PGR type, numerous round mitochondria with areas of lower electron density were present (Fig. 5h, 1). Ni + GA3 cells were particularly rich in peroxisomes (Fig. 5h). The ultrastructure of chloroplasts was altered under Ni exposure. Especially, in palisade cells from $\mathrm{Ni}(+), \mathrm{Ni}+\mathrm{GA} 3$ and $\mathrm{Ni}+\mathrm{BL}$, thylakoids and grana had a looser arrangement, while, in spongy cells, swollen stroma and dilated thylakoids were observed (Fig. $5 \mathrm{~h}-\mathrm{j}$ ). Moreover, in $\mathrm{Ni}(+), \mathrm{Ni}+\mathrm{GA} 3$ and $\mathrm{Ni}+\mathrm{BL}$ treatments, some parts of cell walls excreted a pectin-like substance into the intercellular space (Fig. 5i, m-o).

\section{Biochemical response}

\section{Profile of endogenous phytohormones}

We have separately analyzed differences between the profile of endogenous PGRs in control cultures untreated and treated with $\mathrm{Ni}$ and between $\mathrm{Ni}(+)$-treatments with without and with sPGRs. For the main classes of endogenous PGRs, we determined the level of both active and deactivated compounds and, in the case of cytokinins and gibberellins, also intermediate compounds (Table 3).

Endogenous phytohormones in $\mathrm{Ni}(-)$ and $\mathrm{Ni}(+)$ cultures: the profiles of endogenous PGRs differed substantially between shoots and roots. In the shoots, the contents of active forms of auxins, cytokinins, gibberellins, abscisic acid, and jasmonates were virtually the same in $\mathrm{Ni}(-)$ and $\mathrm{Ni}(+)$ treatments. As a reaction to $\mathrm{Ni}$, an increase occurred in the level of inactive forms of abscisic acid, oxidized auxins, as well as inactive gibberellins. In turn, the level of salicylic acid and conjugated (inactive) auxins decreased (Table 3).

In the $\mathrm{Ni}(+)$ roots, a significant increase occurred in the content of active forms of auxins, cytokinins, gibberellins, and salicylic acid in comparison with $\mathrm{Ni}(-)$ roots (Table 3). Among deactivated auxins, the concentration of 

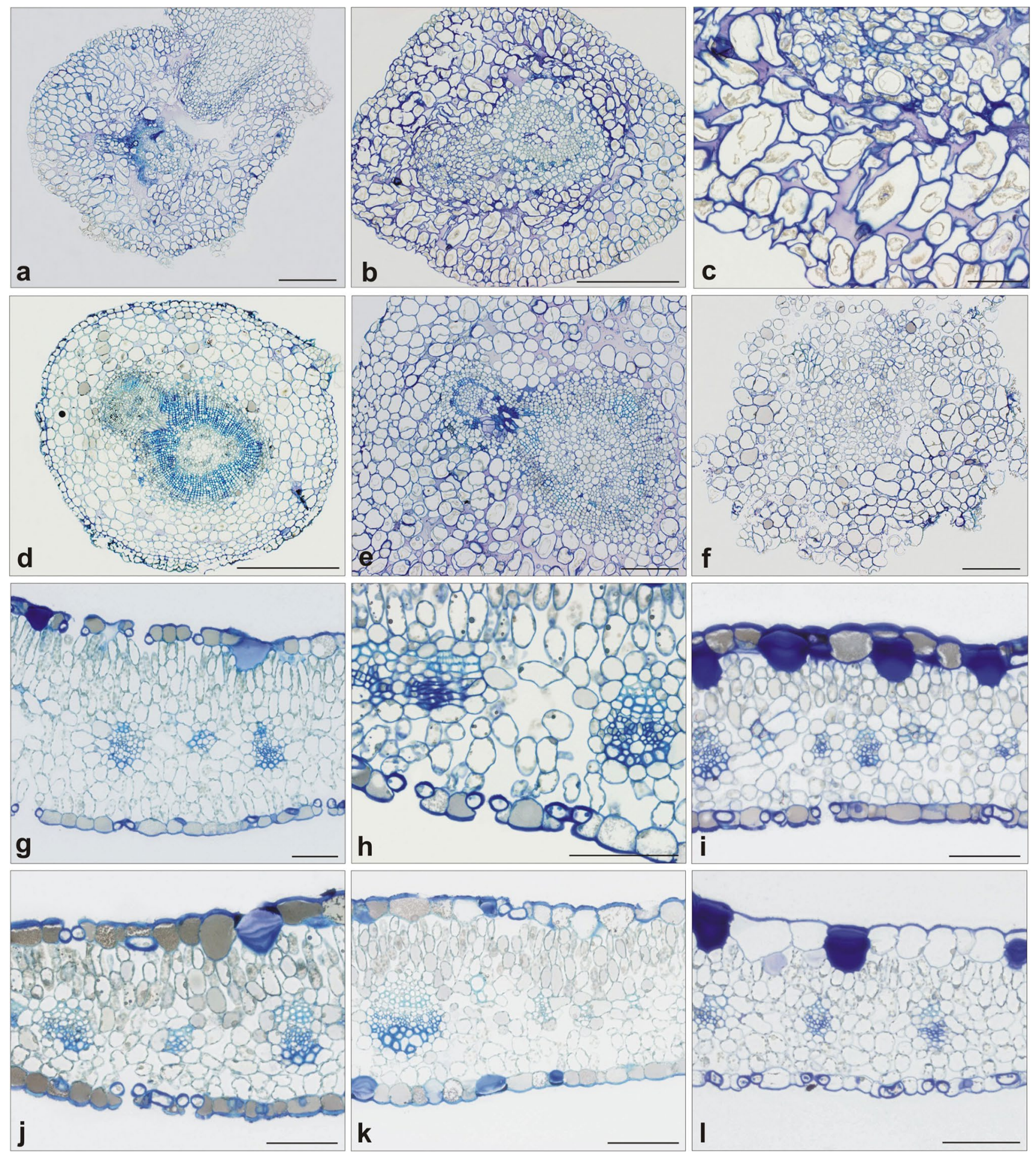

Fig. 3 Anatomical structure of $D$. jasminea shoot bases and leaves treated with $\mathrm{Ni}$ and supplemental phytohormones. a-f Shoot bases. Ni(-) (a); $\mathrm{Ni}(+)(\mathbf{b}, \mathbf{c}) ; \mathrm{Ni}+\mathrm{GA} 3(\mathbf{d}) ; \mathrm{Ni}+\mathrm{BL}(\mathbf{e}) ; \mathrm{Ni}+\mathrm{JA}(\mathbf{f})$. g-l Leaves. Ni(-) (g, h); Ni(+) (i); Ni+JA (j); Ni + BL (k); Ni+GA3 (l) Bar=100 $\mu$ m

conjugated compounds increased under Ni exposure, and the level of oxidized compounds did not differ between $\mathrm{Ni}(-)$ and $\mathrm{Ni}(+)$ roots. The level of both intermediate and deactivated cytokinins increased, and endogenous jasmonates decreased (Table 3). Under Ni exposure, the content of active abscisic acid was not altered; however, inactive ABA glucosyl ester accumulated. 


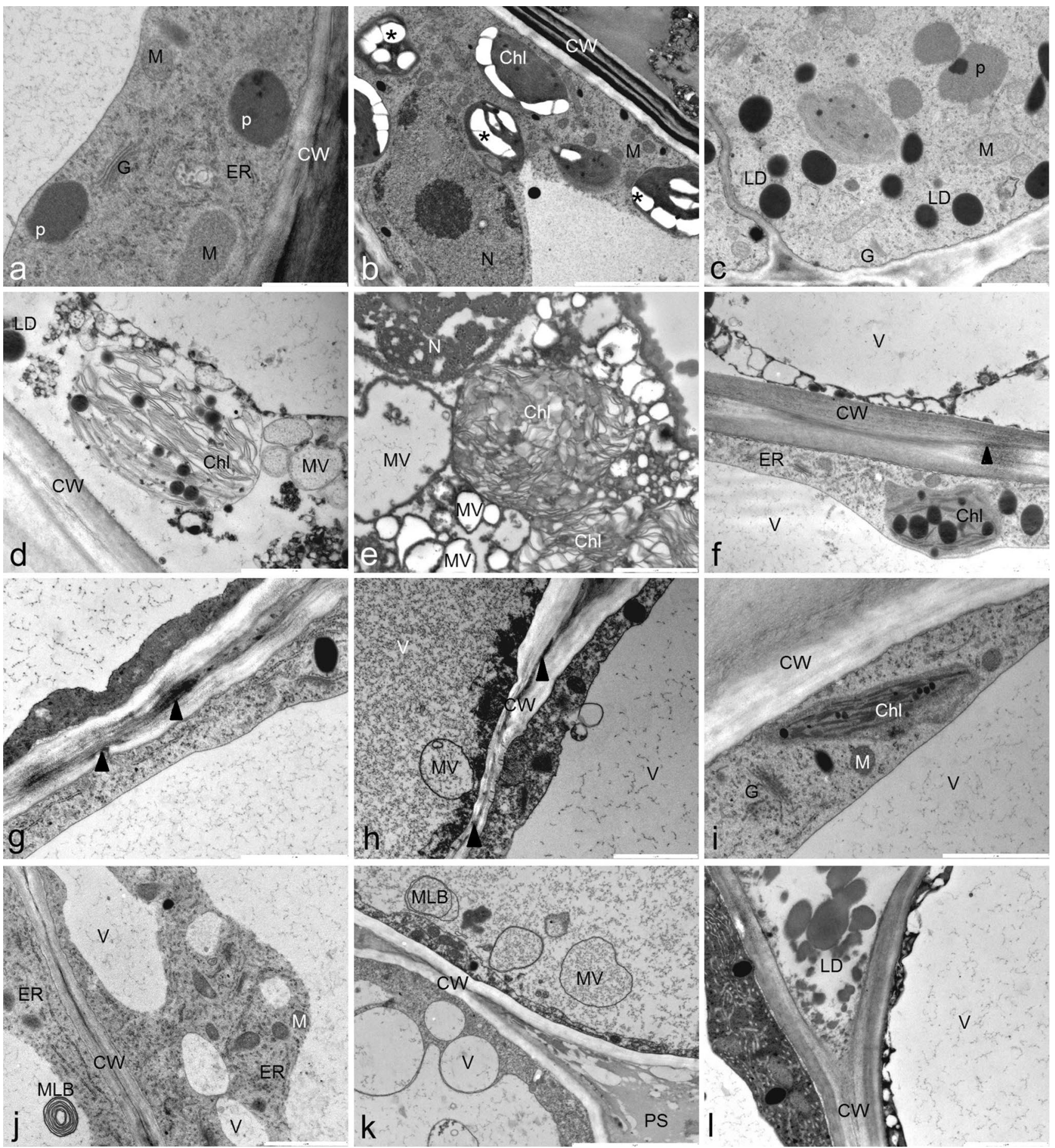

Fig. 4 Cell ultrastructure of $D$. jasminea shoot bases treated with $\mathrm{Ni}$ and supplemental phytohormones. $\mathrm{Ni}(-)(\mathbf{a}-\mathbf{c}) ; \mathrm{Ni}(+)(\mathbf{d}-\mathbf{f}) ; \mathrm{Ni}+\mathrm{JA}$ $(\mathbf{g}, \mathbf{i}, \mathbf{l}) ; \mathrm{Ni}+\mathrm{BL}(\mathbf{h}, \mathbf{k}) ; \mathrm{Ni}+\mathrm{GA} 3(\mathbf{j}) . C W$ cell wall, $N$ nucleus, $G$ golgi apparatus, $V$ vacuole, $M$ mitochondrion, asterisk (*) starch, $C h l$

Endogenous phytohormones in $\mathrm{Ni}(+)$ cultures without and with sPGRs: In the case of shoots, medium supplementation with exogenous GA3 led to the increase in endogenous auxins, especially their conjugates, active chloroplast, $p$ peroxisome, $P S$ pectin-like substance, $E R$ endoplasmatic reticulum, triangle $(\boldsymbol{\Lambda})$ granular deposits, $L D$ lipid droplet, $M L B$ multilamellar body, $M V$ microvesicle

gibberellins, jasmonates, and salicylic acid (Table 3). Application of JA increased the content of active auxins, salicylic acid, and an active form of ABA. The highest increase in active $\mathrm{ABA}$ content occurred in the $\mathrm{Ni}+\mathrm{BL}$ 

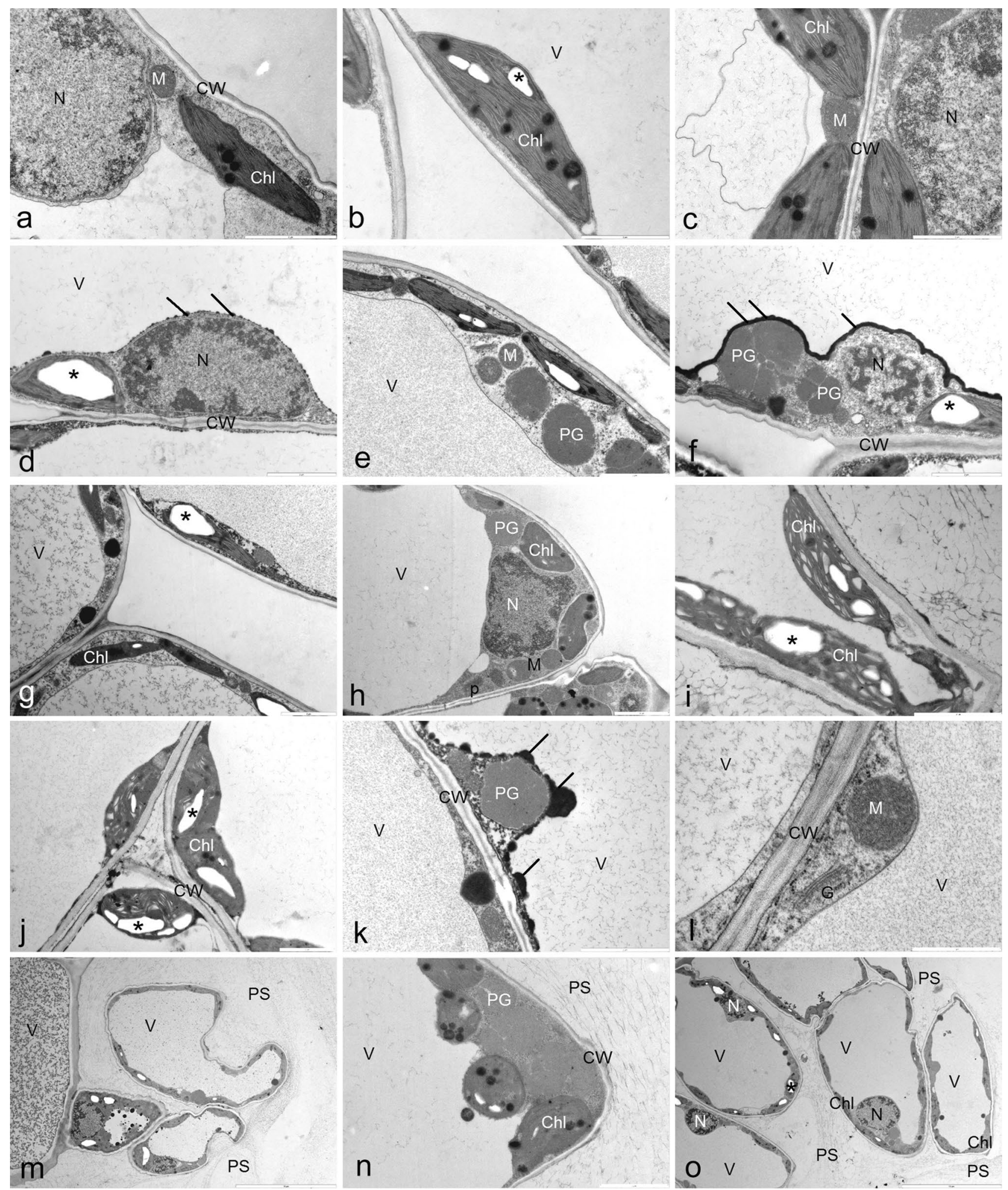

Fig. 5 Cell ultrastructure of D. jasminea leaves treated with $\mathrm{Ni}$ and supplemental phytohormones. $\mathrm{Ni}(-)(\mathbf{a}-\mathbf{c}) ; \mathrm{Ni}(+)(\mathbf{d}, \mathbf{m}) ; \mathrm{Ni}+\mathrm{BL}$ $(\mathbf{e}, \mathbf{i}, \mathbf{j}, \mathbf{l}) ; \mathrm{Ni}+\mathrm{JA}(\mathbf{k}) ; \mathrm{Ni}+\mathrm{GA} 3(\mathbf{h}, \mathbf{n}) . C W$ cell wall, $N$ nucleus, $G$ golgi apparatus, $V$ vacuole, $M$ mitochondrion, asterisk $(*)$ starch, $C h l$ chloroplast, line $(\boldsymbol{)})$ phenolic-like compounds, $P G$ protein grain, $p$ peroxisome, $P S$ pectin-like substance 


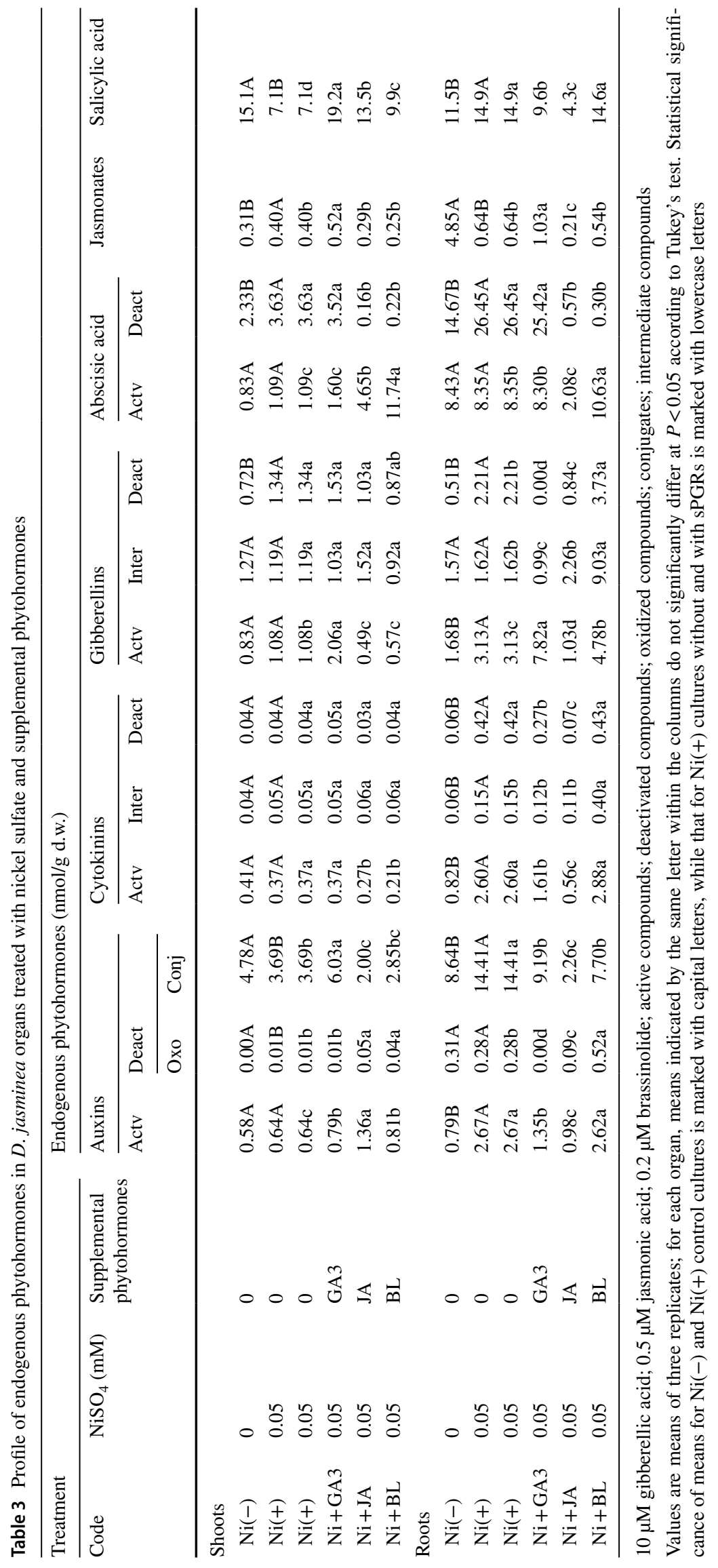


medium. Both JA and BL reduced the concentration of active cytokinins and gibberellins, with a constant proportion of intermediate and deactivated compounds. In addition, these two sPGRs increased the level of oxidized auxins and simultaneously decreased the content of conjugated forms (Table 3 ).

In comparison with roots developed on $\mathrm{Ni}(+)$ medium without sPGRs, in the presence of sPGRs, the content of auxin conjugates was reduced (Table 3 ). Apart from that, each sPGR differentially modulated the level of endogenous PGRs (Table 3). Medium supplementation with GA3 increased the content of active gibberellins and jasmonates. In the presence of GA3 and JA, the concentrations of active and oxidized auxins decreased. JA reduced the content of cytokinins in the roots, especially active and deactivated compounds, as well as free ABA, endogenous jasmonates, and salicylic acid. BL enhanced auxin oxidation, synthesis of cytokinin intermediates, all forms of gibberellins, and an active form of ABA (Table 3). In turn, BL did not affect the content of jasmonates and salicylic acid.

\section{Pigments, phenolic compounds, and radical scavenging activity}

Toxicity of Ni to cultured explants was manifested in the decreased synthesis of photosynthetic pigments, both chlorophylls and carotenoids, in comparison with $\mathrm{Ni}(-)$ treatment (Fig. 6). In $\mathrm{Ni}(+)$ cultures, the application of exogenous phytohormones did not ameliorate pigment accumulation. Total chlorophyll content decreased significantly in $\mathrm{Ni}+\mathrm{JA}$ and $\mathrm{Ni}+\mathrm{BL}$, while, in the case of $\mathrm{Ni}+\mathrm{GA} 3$, it was the same as in $\mathrm{Ni}(+)$ cultures without sPGRs (Fig. 6). No influence of applied sPGRs was observed on the content of carotenoids (Fig. 6).

Considering the phenolic profile of Ni-treated shoots, the content of total phenolics, phenylpropanoids, and flavonols significantly increased in $\mathrm{Ni}+\mathrm{JA}$ and $\mathrm{Ni}+\mathrm{BL}$, in comparison with $\mathrm{Ni}(+)$ treatment without sPGRs (Fig. 7). In contrast, the accumulation of these compounds was significantly reduced in shoots from $\mathrm{Ni}+\mathrm{GA} 3$ medium (Fig. 7). In Ni(+) cultures, all applied sPGRs caused a substantial increase in the anthocyanin content. When compared with $\mathrm{Ni}(-)$ cultures, the presence of $\mathrm{Ni}$ did not enhance the accumulation of phenolic compounds.

Antioxidant capacity of shoot tissues, measured as an efficiency of radical scavenging, was elevated in the presence of Ni (Fig. 8). Medium supplementation with sPGRs, especially GA3 and BL, caused a significant reduction in radical scavenging activity (RSA). Comparing SPGR treatments, the highest radical scavenging activity occurred in $\mathrm{Ni}+$ JA (Fig. 8)
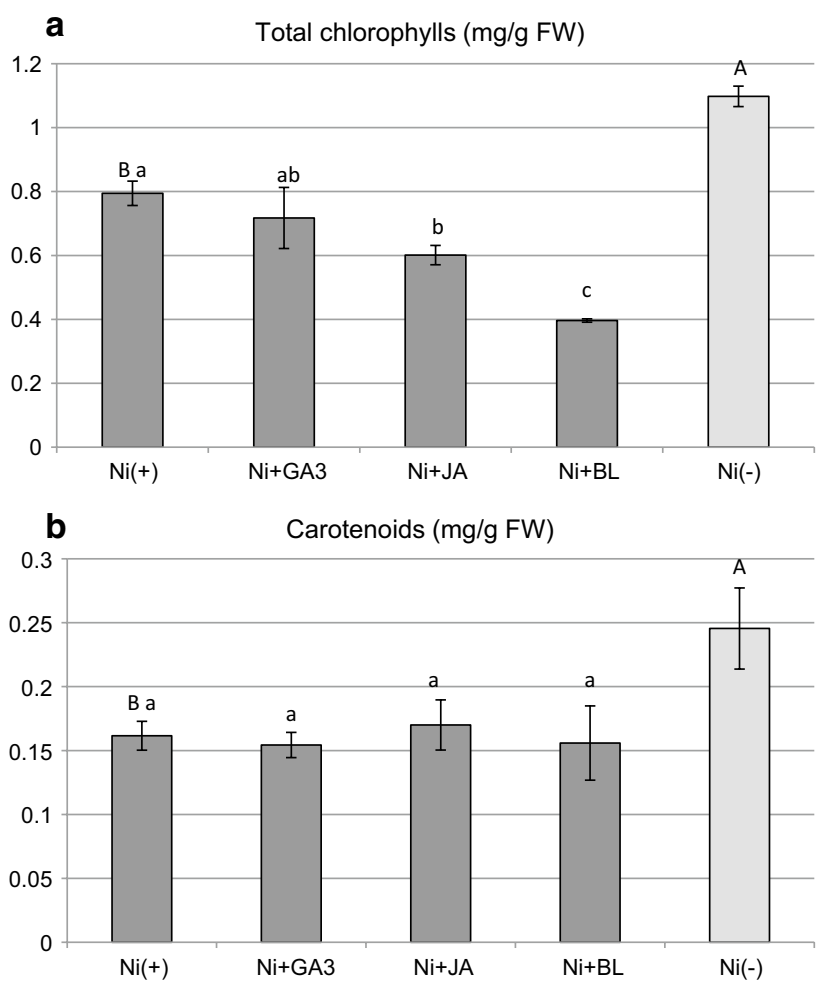

Fig. 6 Content of photosynthetic pigments in D. jasminea shoots treated with $\mathrm{Ni}$ and supplemental phytohormones. Capital letters indicate statistical significance of means $(n=4)$ for $\mathrm{Ni}(-)$ and $\mathrm{Ni}(+)$ treatments. Lowercase letters indicate statistical significance of means $(n=4)$ for $\mathrm{Ni}(+)$ and $\mathrm{Ni}+$ sPGRs treatments

\section{Discussion}

\section{The effects of Ni stress in D. jasminea microplantlets}

Toxicity of Ni to plants was attributed to detrimental effects caused by water, osmotic, and oxidative stresses (Yusuf et al. 2011; Gupta et al. 2017). In our study on D. jasminea toxicity, increasing $\mathrm{Ni}$ concentrations were manifested by inhibited growth, proliferation, and organogenesis. After the initial screening for an optimal, non-lethal Ni level to be applied in shoot cultures, we have evaluated structural and physiological responses to toxic ions.

Our study revealed organ-specific alterations in the content of endogenous phytohormones in D. jasminea exposed to Ni. Analysis of these alterations allows, at least partially, defining mechanisms of nickel toxicity and plant defence reaction. Interestingly, in neither shoots nor roots, enhanced accumulation of free ABA occurred, which is the opposite to the content of ABA glucosyl ester (ABA-GE), an inactive form of ABA. Enhanced synthesis of free ABA is the most common reaction in plants subjected to abiotic stress, such as drought and cold (Peleg and Blumwald 2011). Moreover, heavy metals, including $\mathrm{Ni}$, were reported to cause 


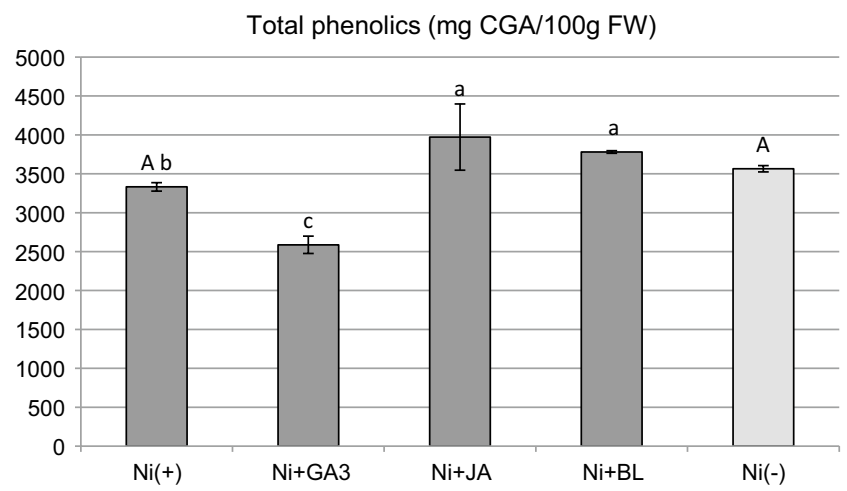

Flavonols (mg QC/100g FW)

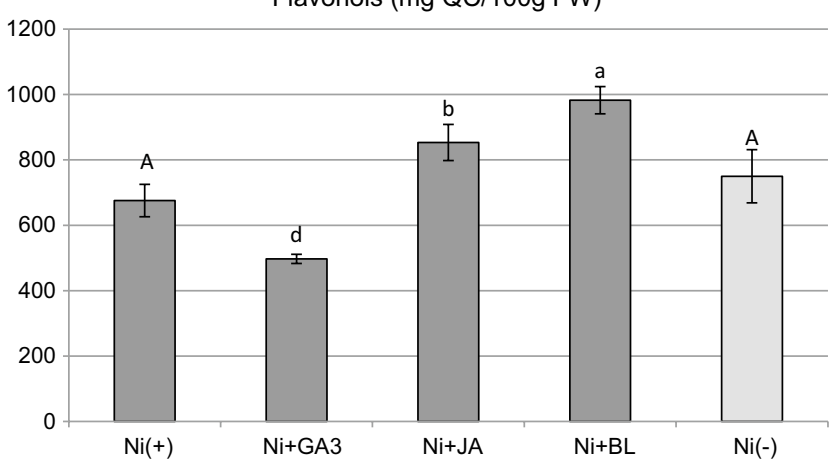

Fig. 7 Profile of phenolic compounds in D. jasminea shoots treated with $\mathrm{Ni}$ and supplemental phytohormones. Capital letters indicate statistical significance of means $(n=4)$ for $\mathrm{Ni}(-)$ and $\mathrm{Ni}(+)$ treatments.

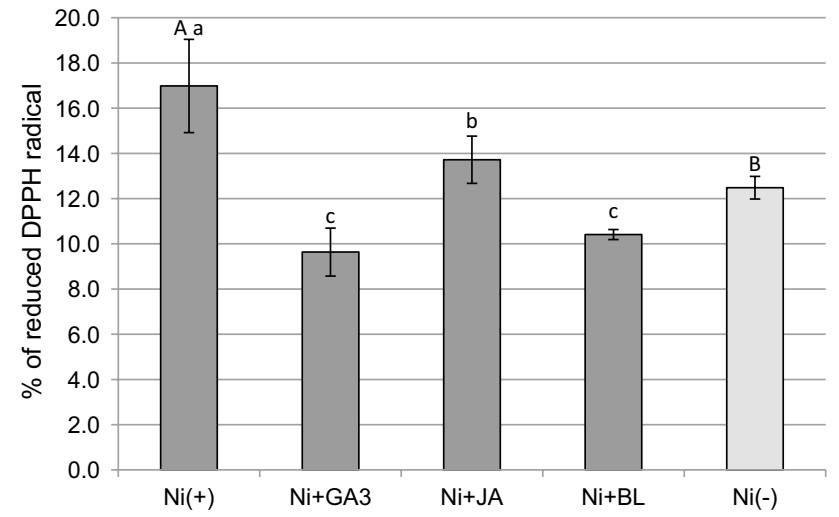

Fig. 8 Radical scavenging activity in D. jasminea shoots treated with $\mathrm{Ni}$ and supplemental phytohormones. Capital letters indicate statistical significance of means $(n=4)$ for $\mathrm{Ni}(-)$ and $\mathrm{Ni}(+)$ treatments. Lowercase letters indicate statistical significance of means $(n=4)$ for $\mathrm{Ni}(+)$ and $\mathrm{Ni}+$ sPGRs treatments. DPPH, 2,2-diphenyl-1-picrylhydrazyl

disturbances in the water status that results in enhanced ABA synthesis (Kim et al. 2014; Vishwakarma et al. 2017). This compound regulates stomata closure in stressed plants, regulating transpiration in unfavourable conditions. However, in our experiment, which was conducted in in vitro culture,
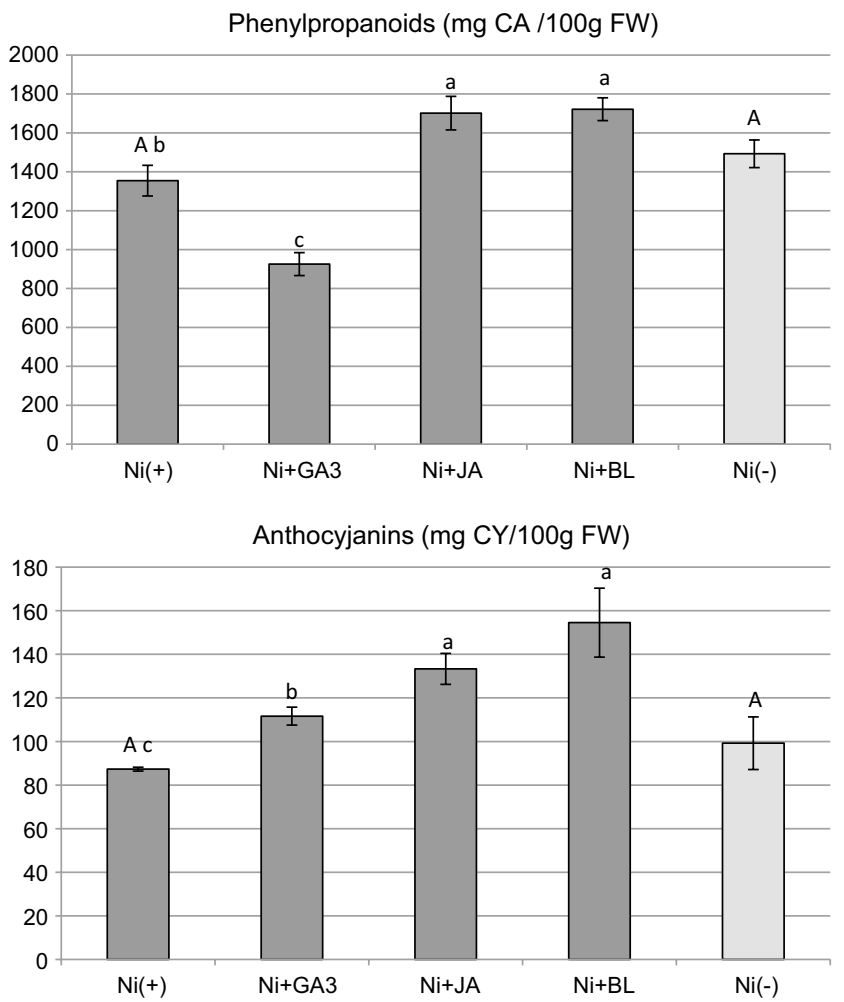

Lowercase letters indicate statistical significance of means $(n=4)$ for $\mathrm{Ni}(+)$ and $\mathrm{Ni}+$ sPGRs treatments

$C G A$ chlorogenic acid, $C A$ caffeic acid, $Q C$ quercetin, $C Y$ cyanidin

toxic effects were unlikely related to water deficiency. The content of free ABA was not altered under $\mathrm{Ni}$ exposure, indicating sufficient water availability. This was confirmed by the anatomical survey, which revealed that $D$. jasminea leaves had opened stomata distributed in both the lower and upper epidermis. On the other hand, the accumulation of ABA-GE, especially pronounced in the roots, suggests the involvement of ABA in Ni stress response. ABA glucosyl ester is regarded as a storage and transport form of $\mathrm{ABA}$ and a root-to-shoot signalling molecule specific to osmotic stress (Piotrowska-Niczyporuk and Bajguz 2011; Burla et al. 2013; Bücker-Neto et al. 2017). Therefore, nickel toxicity in $D$. jasminea can be related to osmotic imbalance that was manifested in enhanced accumulation of ABA-GE. Osmotic instability was associated with a reduction in biomass accretion, as in in vitro cultured Hypericum perforatum (Cui et al. 2010).

In $D$. jasminea shoots, the stress reaction was also manifested by the oxidation of auxins, the accumulation of jasmonates, and the reduction of the salicylic acid content. Oxidation, unlike conjugation, is a way of irreversible inactivation of auxins. It is also linked with elevated ROS production during oxidative stress (Jouili et al. 2011; Peer et al. 2013). We have, therefore, analyzed some aspects of the antioxidant response of $\mathrm{Ni}$-treated shoots. Although radical 
scavenging activity increased, the content of phenolic compounds was virtually unaffected. However, there is an interesting relationship between the content of oxidized auxins and flavonols. The latter are regarded as buffers of cellular ROS levels, and their content is usually negatively correlated with the content of oxidized auxins (Peer et al. 2013). In $D$. jasminea, enhanced production of cellular ROS under $\mathrm{Ni}$ exposure could be attributed to the signal role of ROS generated in the presence of a low dose of nickel rather than to the induction of massive oxidative stress.

Enhanced accumulation of endogenous jasmonates is associated with the toxic action of heavy metals (Gallego et al. 2012). Heavy metals cause the degradation of cellular membranes and the induction of an octodecanoic pathway, leading to synthesis of jasmonates (Maksymiec et al. 2005). As revealed by TEM, in cells of $D$. jasminea, membrane degradation occurred, especially the disintegration of chloroplasts and formation of microvesicles. Moreover, the content of pigments bound to membranes, i.e., chlorophylls and carotenoids, substantially decreased. We can, therefore, assume that the increased accumulation of jasmonates was a consequence of the nickel-induced degradation of cellular membranes.

Interestingly, under Ni stress, Daphne plants were able to maintain (in shoots) or even elevate (in roots) the content of active forms of growth promoters, namely auxins, gibberellins, and cytokinins. Usually, together with increase in ABA content, the level of other endogenous PGRs, especially cytokinins, decreases (Peleg and Blumwald 2011; Piotrowska-Niczyporuk et al. 2012). Reaction in Daphne cultures can be attributed to the hormetic dose effect, in which low doses of toxic agent stimulate the synthesis of growth promoters as a defence reaction (Calabrese and Blain 2009).

\section{Modulatory role of exogenous growth regulators in Ni toxicity}

At the structural level, the most pronounced effect of sPGR application was a limited cellular damage in the inner parts of shoot bases. Shoots developed in $\mathrm{Ni}(+)$ without sPGRs suffered from serious cellular disorganization, mainly the formation of microvesicles and multilamellar bodies, suggesting autophagy (van Doorn et al. 2015), and chloroplast degradation. Such alterations were also apparent in sPGRtreated shoots, but they were limited to the cells of external layers. Inner cells maintained an undisturbed structure, divided, and formed adventitious shoots.

All phytohormones applied in this study are widely reported to increase plant tolerance to heavy metal stress (He et al. 2015; Sirhindi et al. 2016; Singh and Prasad 2017). In $D$. jasminea, exogenous application of sPGRs altered a reaction of propagated shoots to nickel treatment. The most surprising was the fact that BL inhibited shoot proliferation and growth. Recent reports highlight the metal stressameliorating role of various brassinosteroids, including BL (Sharma et al. 2008; Singh and Prasad 2017). Growth inhibition of $D$. jasminea could be the result of enhanced accumulations of $\mathrm{Ni}$ in the presence of BL. In tolerant plants, $\mathrm{Ni}$ is chelated and accumulated in vacuoles, while, in nontolerant plants, it is rather stored in cytoplasm and cell walls (Krämer et al. 2000). In D. jasminea cells of shoots accumulating higher amounts of $\mathrm{Ni}$, namely from $\mathrm{Ni}(+)$ and $\mathrm{Ni}^{+} \mathrm{BL}$ media, we observed substantial alterations in the cell wall structure. The most prominent was the presence of granular metal deposits in the cell wall. In addition, in $\mathrm{Ni}+\mathrm{BL}$, the formation of cell wall channels with granular deposits and secretion of lipids and pectins occurred. Accumulation of waxes and a pectin layer can be considered a defence reaction aimed at restricting the transport of heavy metals, such as $\mathrm{Pb}$ or $\mathrm{Ni}$, into the protoplast (Krzesłowska et al. 2009, 2016; Meychik et al. 2014). Therefore, D. jasminea can be classified as Ni-sensitive species, counteracting Ni toxicity by cell wall reorganization. We noted a strong stress reaction in microplantlets cultured in $\mathrm{Ni}+\mathrm{BL}$ medium, manifested by the increased synthesis of ABA and anthocyanins, as well as an elevated auxin oxidation with a simultaneous decline of radical scavenging activity. The observed stress response indicates that, in the applied culture system, the action of BL enhanced $\mathrm{Ni}$ accumulation to a toxic level. The phenomenon of increased $\mathrm{Ni}$ accumulation in the presence of $\mathrm{BL}$ is discussed below in the following subsection.

GA3 and JA applied to Ni(+) medium restored the capacity of shoot proliferation and biomass accretion to the level observed in untreated shoots. Gibberellic acid substantially ameliorated the growth and physiological condition of $D$. jasminea, which was reflected in the phytohormonal profile. The high level of exogenous GA3 enhanced shoot organogenesis by the stimulation of the synthesis of active forms of gibberellins and auxins, as well as auxin conjugates. The absence of oxidized auxins in the roots and their low level in the shoots indicated the repression of auxin deactivation in the presence of GA3. Interestingly, as revealed by extract analysis and anatomical survey, the accumulation of phenolic compounds was significantly inhibited. There is evidence that exogenous gibberellins may reduce the content of phenolic compounds in plant tissues and interplay with antioxidant capacity (Tian et al. 2011). Therefore, we can assume that non-enzymatic antioxidants were not likely involved in antioxidant response of $D$. jasminea subjected to $\mathrm{Ni}+\mathrm{GA} 3$. On the other hand, in leaf cells from this treatment, numerous peroxisomes were present, suggesting that some oxidative processes were stimulated. It can be related to the substantial accumulation of endogenous $\mathrm{JA}$ in the presence of GA3, since JA production is carried out in peroxisomes via controlled $\beta$-oxidation (León 2013). 
The increased content of endogenous jasmonates is often associated with enhanced tolerance to heavy metal stress (Maksymiec et al. 2005; Yan et al. 2013). This supports our finding that supplemental application of GA3 contributed to higher Ni tolerance in D. jasminea. In this case, the mechanism responsible for enhanced $\mathrm{Ni}$ tolerance may be related to balanced phytohormone synthesis, namely the production of endogenous JA and metabolically active growth promoters (auxins and gibberellins).

Exogenous JA also ameliorated multiplication and growth parameters of $D$. jasminea shoots under Ni exposure. This reaction could be related to enhanced synthesis of active auxins and salicylic acid. As reported by Della Rovere et al. (2013), the meristematic capacity of cells is induced by auxin accumulation. The observed formation of numerous meristematic centres in $\mathrm{Ni}+\mathrm{JA}$-treated stem bases could be a result of the stimulation of auxin accumulation in the shoots. The amelioration of growth response could also be attributed to enhanced antioxidant activity. Jasmonates are known to mitigate oxidative stress through the induction of antioxidant components, both enzymatic and non-enzymatic (Farooq et al. 2016; Sirhindi et al. 2016). In our study, the increased antioxidant response after $\mathrm{Ni}+\mathrm{JA}$ treatment was manifested by a higher content of phenolic compounds and a considerably high radical scavenging activity (in comparison with other sPGRs). On the other hand, an increased content of endogenous ABA and the decreased accumulation of gibberellins suggest that exogenous JA was also involved in the processes of inhibitory character. Stress reactions were unlikely related only to $\mathrm{Ni}$ accumulation, since this process was significantly restricted. The main reason of stress reaction in $\mathrm{Ni}+\mathrm{JA}$-treated plants seemed to be the enhanced digestion of cellular components. At the ultrastructural level, the formation of vesicles and multilamellar bodies as well as the disorganization of the chloroplast structure were observed. It was recently found that exogenous jasmonates may activate the chlorophyll degradation machinery (Zhu et al. 2015). Rapid decline in the content of chlorophyll supports this explanation of stress reaction in $\mathrm{Ni}+\mathrm{JA}$-treated $D$. jasminea.

\section{Effect of sPGRs on Ni accumulation in cultured shoots}

The use of sPGRs was also applied for enhancing Ni uptake by cultured shoots. It was surprising to reveal that only BL enhanced $\mathrm{Ni}$ accumulation in D. jasminea. The uptake of heavy metals usually decreases when plants are treated with stress hormones due to restricted transpiration and stomatal closure (Bücker-Neto et al. 2017). In general, brassinosteroids influence the redistribution of metals between shoots and roots (Wang et al. 2015; Waisi et al. 2017). However, despite the fact that these compounds reduce metal translocation from roots to shoots, preferential binding of some heavy metals in the roots may occur (Sharma et al. 2008; Singh and Prasad 2017; Xu et al. 2018). On the other hand, there are single reports on the promoting effect of BL on Ni translocation, such as in the hyperaccumulator Solanum nigrum (Soares et al. 2016). This phenomenon was attributed to the mechanism aimed at the protection of roots. In our study, an explanation of enhanced $\mathrm{Ni}$ accumulation may be simpler, because, although $D$. jasminea cultured in vitro rooted poorly in the presence of $\mathrm{Ni}$ and $\mathrm{BL}, \mathrm{Ni}$ could be absorbed directly by the shoot base immersed in the culture medium. The way that BL promoted direct Ni uptake remains still to be construed. As these compounds are not likely involved in long-distance transport (Lacombe and Achard 2016), the observed reaction could be related to phenomena existing in the intact zone between the shoot base and the culture medium; for instance, cell wall rearrangements or synthesis of organic acids of metal-chelating properties.

It was reported that application of brassinosteroids exerts different effects on metal accumulation in plants, either increasing or decreasing their uptake depending on the applied form of BL, its concentration, or type of metal ion (Sharma et al. 2008; Xu et al. 2018). Therefore, further research is needed to clarify the role of BL in Ni accumulation and in D. jasminea response to metal stress.

The exogenous application of GA3 did not affect Ni accumulation in D. jasminea plantlets, compared to nonsPGRs Ni(+) treatment. Similarly, Meng et al. (2009) did not observe any influence of exogenous GA3 on internal Cd accumulation in Brassica napus. This reaction was rather unusual, since GA3 was reported to be involved in alteration of the membrane permeability and regulation of membrane transport processes, leading to a decrease in metal uptake (Rubio et al. 1994; Moya et al. 1995). This reduction of Ni accumulation in GA3-treated plants was observed in Ni-hyperaccumulating species of Alyssum and Noccaea (Cabello-Conejo et al. 2014) or non-accumulating specimens of Vigna radiata (Ali et al. 2015).

It was found that JA and its derivative, methyl jasmonate (MeJA), significantly inhibit the uptake of heavy metals by the reduction in transpiration rate (Piotrowska et al. 2009; Chen et al. 2014). In our study, the decreased Ni concentration in D. jasminea shoots was unlikely related to a disturbed water balance, since the experiment was held in high humidity of in vitro culture and leaf stomata were opened. The uptake of $\mathrm{Ni}$ could be repressed by an increased concentration of phenolic compounds in D. jasminea shoots treated with $\mathrm{Ni}+\mathrm{JA}$. The relationship between heavy metal accumulation and the synthesis of phenolic compounds could be in agreement with the findings of Kováčik et al. (2011) and Chen et al. (2014). They concluded that exogenous application of MeJA inhibits $\mathrm{Ni}, \mathrm{Cd}$, and As uptake by enhanced 
accumulation of phenolics in Matricaria chamomilla and Kandelia obovata plants.

\section{Conclusions}

Nickel toxicity to Daphne jasminea was attributed to enhanced synthesis of growth inhibitors, mainly ABA, in cultured shoots. Medium supplementation with exogenous GA3, JA, and BL was applied as a strategy to ameliorate plant growth and to stimulate the defence system under unfavourable conditions. The tested sPGRs differentially modulated the plant response, activating various defence pathways, from the stimulation of peroxisomal reactions for increased JA accumulation, via synthesis of endogenous growth promoters, such as active auxins and salicylic acid, to cell wall rearrangements. Our main message is that the action of exogenous PGRs may either increase plant tolerance to Ni stress, or elevate the stress itself, especially when an accumulation of toxic metal is facilitated. In in vitro culture with explants subjected to external phytohormonal stimuli, the combined effects of supplemental compounds may modulate plant growth and tolerance levels.

Author contribution statement Conception and design: AW and EHF. Analysis and interpretation of the data: AW, EM, KD, and MD. Drafting of the article: AW and EM. Critical revision of the article for important intellectual content: AW and EHF. Final approval of the article: AW, EM, EHF, KD, and MD. Statistical expertise: AW, KD, and MD. Obtaining of funding: AW and EHF. Collection and assembly of data: $\mathrm{AW}, \mathrm{EM}, \mathrm{KD}$, and MD.

Acknowledgements The study was financed by Polish Ministry of Science and Higher Education (DS 3500) granted to the University of Agriculture in Kraków, Poland.

Open Access This article is distributed under the terms of the Creative Commons Attribution 4.0 International License (http://creativeco mmons.org/licenses/by/4.0/), which permits unrestricted use, distribution, and reproduction in any medium, provided you give appropriate credit to the original author(s) and the source, provide a link to the Creative Commons license, and indicate if changes were made.

\section{References}

Ali MA, Asghar HN, Khan MY, Saleem M, Naveed M, Niazi NK (2015) Alleviation of nickel-induced stress in mungbean through application of gibberellic acid. Int J Agric Biol 17:990-994. https ://doi.org/10.17957/IJAB/15.0001

Asgher M, Khan MIR, Anjum NA, Khan NA (2015) Minimising toxicity of cadmium in plants-role of plant growth regulators. Protoplasma 252:399-413. https://doi.org/10.1007/s00709-014-0710-4
Ater M, Lefèbvre C, Gruber W, Meerts P (2000) A phytogeochemical survey of the flora of ultramafic and adjacent normal soils in North Morocco. Plant Soil 218:127-135

Atici Ö, Ağar G, Battal P (2005) Changes in phytohormone contents in chickpea seeds germinating under lead or zinc stress. Biol Plant 49:215-222. https://doi.org/10.1007/s10535-005-5222-9

Bajguz A (2011) Suppression of Chlorella vulgaris growth by cadmium, lead, and copper stress and its restoration by endogenous brassinolide. Arch Environ Contam Toxicol 60:406-416. https ://doi.org/10.1007/s00244-010-9551-0

Bajguz A, Hayat S (2009) Effects of brassinosteroids on the plant responses to environmental stresses. Plant Physiol Biochem 47:1-8. https://doi.org/10.1016/j.plaphy.2008.10.002

Bani A, Imeri A, Echevarria G, Pavlova D, Reeves RD, Morel JL, Sulçe $S$ (2013) Nickel hyperaccumulation in the serpentine flora of Albania. Fresenius Environ Bull 22:1792-1801. https://doi. org/10.1006/anbo.1998.0786

Boer JL, Mulrooney SB, Hausinger RP (2014) Nickel-dependent metalloenzymes. Arch Biochem Biophys 544:142-152. https:// doi.org/10.1016/j.abb.2013.09.002

Bücker-Neto L, Paiva ALS, Machado RD, Arenhart RA, MargisPinheiro M (2017) Interactions between plant hormones and heavy metals responses. Genet Mol Biol 40:373-386. https:// doi.org/10.1590/1678-4685-gmb-2016-0087

Bulak P, Walkiewicz A, Brzezińska M (2014) Plant growth regulators-assisted phytoextraction. Biol Plant 58:1-8. https://doi. org/10.1007/s10535-013-0382-5

Burla B, Pfrunder S, Nagy R, Francisco RM, Lee Y, Martinoia E (2013) Vacuolar transport of abscisic acid glucosyl ester is mediated by ATP-binding cassette and proton-antiport mechanisms in Arabidopsis. Plant Physiol 163:1446-1458. https://doi. org/10.1104/pp.113.222547

Cabello-Conejo MI, Centofanti T, Kidd PS, Prieto-Fernandez A, Chaney RL (2013) Evaluation of plant growth regulators to increase nickel phytoextraction by Alyssum species. Int J Phytoremediation 15:365-375. https://doi.org/10.1080/15226 514.2012.702806

Cabello-Conejo MI, Prieto-Fernandez A, Kidd PS (2014) Exogenous treatments with phytohormones can improve growth and nickel yield of hyperaccumulating plants. Sci Total Environ 494-495:1-8. https://doi.org/10.1016/j.scitotenv.2014.06.102

Calabrese EJ, Blain RB (2009) Hormesis and plant biology. Environ Pollut 157:42-48. https://doi.org/10.1016/j.envpol.2008.07.028

Chen C, Huang D, Liu J (2009) Functions and toxicity of nickel in plants: recent advances and future prospects. Clean Soil Air Water 37:304-313. https://doi.org/10.1002/clen.200800199

Chen J, Yan Z, Li X (2014) Effect of methyl jasmonate on cadmium uptake and antioxidative capacity in Kandelia obovata seedlings under cadmium stress. Ecotoxicol Environ Saf 104:349-356. https://doi.org/10.1016/j.ecoenv.2014.01.022

Cui X-H, Murthy HN, Wu C-H, Paek K-Y (2010) Sucrose-induced osmotic stress affects biomass, metabolite, and antioxidant levels in root suspension cultures of Hypericum perforatum $\mathrm{L}$. Plant Cell Tissue Org 103:7-14. https://doi.org/10.1007/s1124 0-010-9747-z

Della Rovere F, Fattorini L, D’Angeli S, Veloccia A, Falasca G, Altamura MM (2013) Auxin and cytokinin control formation of the quiescent centre in the adventitious root apex of Arabidopsis. Ann Bot 112:1395-1407. https://doi.org/10.1093/aob/mct215

Dziurka M, Janeczko A, Juhász C, Gullner G, Oklestkova J, Novak O, Saja D, Skoczowski A, Tobias I, Barna B (2016) Local and systemic hormonal responses in pepper leaves during compatible and incompatible pepper-tobamovirus interactions. Plant Physiol Biochem 109:355-364. https://doi.org/10.1016/j.plaphy.2016.10.013 
Fabiano CC, Tezotto T, Favarin JL, Polacco JC, Mazzafera P (2015) Essentiality of nickel in plants: a role in plant stresses. Front Plant Sci 6:2013-2016. https://doi.org/10.3389/fpls.2015.00754

Farooq MA, Gill RA, Islam F, Ali B, Liu H, Xu J, He S, Zhou W (2016) Methyl jasmonate regulates antioxidant defense and suppresses arsenic uptake in Brassica napus L. Front Plant Sci 7:468. https ://doi.org/10.3389/fpls.2016.00468

Fukumoto LRF, Mazza G (2000) Assessing antioxidant and prooxidant activities of phenolic compounds. J Agric Food Chem 48(8):3597-3604. https://doi.org/10.1021/JF000220W

Gallego SM, Pena LB, Barcia RA, Azpilicueta CE, Iannone MF, Rosales EP, Zawoznik MS, Groppa MD, Benavides MP (2012) Unravelling cadmium toxicity and tolerance in plants: insight into regulatory mechanisms. Environ Exp Bot 83:33-46. https://doi. org/10.1016/j.envexpbot.2012.04.006

Gangwar S, Singh VP, Tripathi DK, Chauhan SM, Maurya JN (2014) Plant responses to metal stress: emerging role of plant growth hormones (auxins, gibberellins and cytokinins) in toxicity alleviation. In: Ahmad P, Rasool S (eds) Emerging technologies and management of crop stress tolerance, vol 2. Elsevier-Academic Press, New York, pp 215-248

Gemrotová M, Kulkarni MG, Stirk WA, Strnad M, Van Staden J, Spichal L (2013) Seedlings of medicinal plants treated with either a cytokinin antagonist (PI-55) or an inhibitor of cytokinin degradation (INCYDE) are protected against the negative effects of cadmium. Plant Growth Regul 71:137-145. https://doi.org/10.1007/ s10725-013-9813-8

Gupta V, Jatav PK, Verma R, Kothari SL, Kachhwaha S (2017) Nickel accumulation and its effect on growth, physiological and biochemical parameters in millets and oats. Environ Sci Pollut Res 24:23915-23925. https://doi.org/10.1007/s11356-017-0057-4

Han Y, Wang S, Zhao N, Deng S, Zhao C, Li N, Sun J, Zhao R, Yi H, Shen X, Chen S (2016) Exogenous abscisic acid alleviates cadmium toxicity by restricting $\mathrm{Cd}^{2+}$ influx in Populus euphratica cells. J Plant Growth Regul 35:827-837. https://doi.org/10.1007/ s00344-016-9585-2

He S, He Z, Wu Q, Wang L, Zhang X (2015) Effects of GA 3 on plant physiological properties, extraction, subcellular distribution and chemical forms of $\mathrm{Pb}$ in Lolium perenne. Int $\mathrm{J}$ Phytoremediation 17:1153-1159. https://doi.org/10.1080/15226514.2015.1045124

Hura T, Dziurka M, Hura K, Ostrowska A, Dziurka K, Gadzinowska J (2017) Wheat and rye genome confer specific phytohormone profile features and interplay under water stress in two phenotypes of triticale. Plant Physiol Biochem 118:494-509. https:// doi.org/10.1016/j.plaphy.2017.07.016

Jouili H, Bouazizi H, El Ferjani E (2011) Plant peroxidases: biomarkers of metallic stress. Acta Physiol Plant 33:2075-2082. https://doi. org/10.1007/s11738-011-0780-2

Karnovsky MJ (1965) A formaldehyde-glutaraldehyde fixative of high osmolality for use in electron microscopy. Cell Biol Source J Cell Biol 27:1-149

Kaur R, Yadav P, Thukral AK, Sharma A, Bhardwaj R, Alyemeni MN, Wijaya L, Ahmad P (2018) Castasterone and citric acid supplementation alleviates cadmium toxicity by modifying antioxidants and organic acids in Brassica juncea. J Plant Growth Regul 37:286-299. https://doi.org/10.1007/s00344-017-9727-1

Kim Y-H, Khan A, Kim D-H, Lee SY, Kim KM, Waqas M, Jung HY, Shin JH, Kim JG, Lee IJ (2014) Silicon mitigates heavy metal stress by regulating P-type heavy metal ATPases, Oryza sativa low silicon genes, and endogenous phytohormones. BMC Plant Biol 14:13. https://doi.org/10.1186/1471-2229-14-13

Kováčik J, Klejdus B, Štork F, Hedbavny J (2011) Nitrate deficiency reduces cadmium and nickel accumulation in chamomile plants. J Agric Food Chem 59:5139-5149. https://doi.org/10.1021/jf104 $793 \mathrm{~b}$
Krämer U, Pickering IJ, Prince RC, Raskin I, Salt DE (2000) Subcellular localization and speciation of nickel in hyperaccumulator and non-accumulator Thlaspi species. Plant Physiol 122:1343-1353. https://doi.org/10.1104/pp.122.4.1343

Krzesłowska M, Lenartowska M, Mellerowicz EJ, Samardakiewicz S, Woźny A (2009) Pectinous cell wall thickenings formationa response of moss protonemata cells to lead. Environ Exp Bot 65:119-131. https://doi.org/10.1016/j.envexpbot.2008.05.006

Krzesłowska M, Rabęda I, Basińska A, Lewandowski M, Mellerowicz EJ, Napieralska A, Samardakiewicz S, Woźny A (2016) Pectinous cell wall thickenings formation - a common defense strategy of plants to cope with $\mathrm{Pb}$. Environ Pollut 214:354-361. https://doi. org/10.1016/j.envpol.2016.04.019

Lacombe B, Achard P (2016) Long-distance transport of phytohormones through the plant vascular system. Curr Opin Plant Biol 34:1-8. https://doi.org/10.1016/j.pbi.2016.06.007

León J (2013) Role of plant peroxisomes in the production of jasmonic acid-based signals. In: del Rio LA (ed) Peroxisomes and their key role in cellular signalling and metabolism, vol 69. Subcellular biochemistry. Springer, Dordrecht, pp 299-313

Lloyd G, McCown B (1980) Commercially-feasible micropropagation of mountain laurel, Kalmia latifolia, by use of shoot-tip culture. Int Plant Propag Soc 30:421-427

Maksymiec W, Wianowska D, Dawidowicz AL, Radkiewicz S, Mardarowicz M, Krupa Z (2005) The level of jasmonic acid in Arabidopsis thaliana and Phaseolus coccineus plants under heavy metal stress. J Plant Physiol 162:1338-1346. https://doi.org/10.1016/j. jplph.2005.01.013

Matraszek R, Hawrylak-Nowak B, Chwil S, Chwil M (2016) Macronutrient composition of nickel-treated wheat under different sulfur concentrations in the nutrient solution. Environ Sci Pollut Res 23:5902-5914. https://doi.org/10.1007/s11356-015-5823-6

Meng H, Hua S, Shamsi IH, Jilani G, Li Y, Jiang L (2009) Cadmiuminduced stress on the seed germination and seedling growth of Brassica napus L., and its alleviation through exogenous plant growth regulators. Plant Growth Regul 58:47-59. https://doi. org/10.1007/s10725-008-9351-y

Meychik N, Nikolaeva Y, Kushunina M, Yermakov I (2014) Are the carboxyl groups of pectin polymers the only metal-binding sites in plant cell walls? Plant Soil 381:25-34. https://doi.org/10.1007/ s11104-014-2111-z

Moya JL, Ros R, Picazo I (1995) Heavy metal-hormone interactions in rice plants: effects on growth, net photosynthesis, and carbohydrate distribution. J Plant Growth Regul 14:61-67. https://doi. org/10.1007/BF00203115

Muhammad S, Shah MT, Khan S, Saddique U, Gul N, Khan MU, Malik RN, Farooq M, Naz A (2013) Wild plant assessment for heavy metal phytoremediation potential along the mafic and ultramafic terrain in northern pakistan. Biomed Res Int. https://doi. org/10.1155/2013/194765

Peer WA, Cheng Y, Murphy AS (2013) Evidence of oxidative attenuation of auxin signalling. J Exp Bot 64:2629-2639. https://doi. org/10.1093/jxb/ert152

Pekkarinen SS, Stöckmann H, Schwarz K, Heinonen IM, Hopia AI (1999) Antioxidant activity and partitioning of phenolic acids in bulk and emulsified methyl linoleate. J Agric Food Chem 47:3036-3043

Peleg Z, Blumwald E (2011) Hormone balance and abiotic stress tolerance in crop plants. Curr Opin Plant Biol 14:290-295. https://doi. org/10.1016/j.pbi.2011.02.001

Pietrini F, Iori V, Cheremisina A, Shevyakova NI, Radyukina N, Kuznetsov VV, Zacchini M (2015) Evaluation of nickel tolerance in Amaranthus paniculatus L. plants by measuring photosynthesis, oxidative status, antioxidative response and metal-binding molecule content. Environ Sci Pollut Res. https://doi.org/10.1007/ s11356-014-3349-y 
Piotrowska A, Bajguz A, Godlewska-Żyłkiewicz B, Czerpak R, Kamińska M (2009) Jasmonic acid as modulator of lead toxicity in aquatic plant Wolffia arrhiza (Lemnaceae). Environ Exp Bot 66:507-513. https://doi.org/10.1016/j.envexpbot.2009.03.019

Piotrowska-Niczyporuk A, Bajguz A (2011) Conjugates of abscisic acid, brassinosteroids, ethylene, gibberellins, and jasmonates. Phytochemistry 72:2097-2112. https://doi.org/10.1016/j.phyto chem.2011.08.012

Piotrowska-Niczyporuk A, Bajguz A, Zambrzycka E, GodlewskaŻyłkiewicz B (2012) Phytohormones as regulators of heavy metal biosorption and toxicity in green alga Chlorella vulgaris (Chlorophyceae). Plant Physiol Biochem 52:52-65. https://doi. org/10.1016/j.plaphy.2011.11.009

Rubio MI, Escrig I, Martinez-Cortina C, Lopez-Benet FJ, Sanz A (1994) Cadmium and nickel accumulation in rice plants. Effects on mineral nutrition and possible interactions of abscisic and gibberellic acids. Plant Growth Regul 14:151-157. https://doi. org/10.1007/BF00025217

Saeidi-sar S, Khavari-nejad RA, Fahimi H, Ghorbanli M, Majd A (2007) Interactive effects of gibberellin A3 and ascorbic acid on lipid peroxidation and antioxidant enzyme activities in glycine max seedlings under nickel stress. Russ J Plant Physiol 54:74-79. https://doi.org/10.1134/S1021443707010116

Seregin IV, Kozhevnikova AD (2006) Physiological role of nickel and its toxic effects on higher plants. Russ J Plant Physiol 53:257-277. https://doi.org/10.1134/S1021443706020178

Sharma P, Bhardwaj R, Arora N, Arora HK, Kumar A (2008) Effects of 28-homobrassinolide on nickel uptake, protein content and antioxidative defence system in Brassica juncea. Biol Plant 52:767-770. https://doi.org/10.1007/s10535-008-0149-6

Siddiqui MH, Al-Whaibi MH, Basalah MO (2011) Interactive effect of calcium and gibberellin on nickel tolerance in relation to antioxidant systems in Triticum aestivum L. Protoplasma 248:503-511. https://doi.org/10.1007/s00709-010-0197-6

Singh S, Prasad SM (2017) Effects of 28-homobrassinoloid on key physiological attributes of Solanum lycopersicum seedlings under cadmium stress: photosynthesis and nitrogen metabolism. Plant Growth Regul 82:161-173. https://doi.org/10.1007/s1072 5-017-0248-5

Singh S, Singh A, Bashri G, Prasad SM (2016) Impact of Cd stress on cellular functioning and its amelioration by phytohormones: an overview on regulatory network. Plant Growth Regul 80:253-263. https://doi.org/10.1007/s10725-016-0170-2

Sirhindi G, Mir MA, Abd-Allah EF, Ahmad P, Gucel S (2016) Jasmonic acid modulates the physio-biochemical attributes, antioxidant enzyme activity, and gene expression in Glycine max under nickel toxicity. Front Plant Sci 7:591. https://doi.org/10.3389/ fpls.2016.00591

Soares C, de Sousa A, Pinto A, Azenha M, Teixeira J, Azevedo RA, Fidalgo F (2016) Effect of 24-epibrassinolide on ROS content, antioxidant system, lipid peroxidation and Ni uptake in Solanum nigrum L. under Ni stress. Environ Exp Bot 122:115-125. https ://doi.org/10.1016/j.envexpbot.2015.09.010

Tian S, Wang Y, Du G, Li Y (2011) Changes in contents and antioxidant activity of phenolic compounds during gibberellin-induced development in Vitis vinifera L. "Muscat". Acta Physiol Plant 33:2467-2475. https://doi.org/10.1007/s11738-011-0791-z van Doorn WG, Kirasak K, Ketsa S (2015) Macroautophagy and microautophagy in relation to vacuole formation in mesophyll cells of Dendrobium tepals. J Plant Physiol 177:67-73. https:// doi.org/10.1016/j.jplph.2015.01.006

Vishwakarma K, Upadhyay N, Kumar N, Yadav G, Singh J, Mishra RK, Kumar V, Verma R, Upadhyay RG, Pandey M, Sharma S (2017) Abscisic acid signaling and abiotic stress tolerance in plants: a review on current knowledge and future prospects. Front Plant Sci 8:161. https://doi.org/10.3389/fpls.2017.00161

Waisi H, Petkovic AZ, Nikolic B, Jankovic BZ, Raicevic VB, Lalevic BT, Giba ZS (2017) Influence of 24-epibrassinolide on seedling growth and distribution of mineral elements in two maize hybrids. Hem Ind 71:201-209. https://doi.org/10.2298/HEMIN D160318030W

Wang B, Li G, Zhang WH (2015) Brassinosteroids are involved in $\mathrm{Fe}$ homeostasis in rice (Oryza sativa L.). J Exp Bot 66:2749-2761. https://doi.org/10.1093/jxb/erv079

Wellburn AR (1994) The spectral determination of chlorophylls a and $\mathrm{b}$, as well as total carotenoids, using various solvents with spectrophotometers of different resolution. J Plant Physiol 144:307-313. https://doi.org/10.1016/S0176-1617(11)81192-2

Wiszniewska A, Hanus-Fajerska E, Smoleń S, Muszyńska E (2015) In vitro selection for lead tolerance in shoot culture of Daphne species. Acta Sci Pol Hortorum Cultus 14:129-142

Wiszniewska A, Hanus-Fajerska E, Muszyńska E, Ciarkowska K (2016) Natural organic amendments for improved phytoremediation of polluted soils: a review of recent progress. Pedosphere 26:1-12. https://doi.org/10.1016/S1002-0160(15)60017-0

Wiszniewska A, Hanus-Fajerska E, Muszyńska E, Smoleń S (2017a) Comparative assessment of response to cadmium in heavy metaltolerant shrubs cultured in vitro. Water Air Soil Pollut 228:304. https://doi.org/10.1007/s11270-017-3488-0

Wiszniewska A, Muszyńska E, Hanus-Fajerska E, Smoleń S, Dziurka M, Dziurka K (2017b) Organic amendments enhance Pb tolerance and accumulation during micropropagation of Daphne jasminea. Environ Sci Pollut Res 24:2421-2432. https://doi.org/10.1007/ s11356-016-7977-2

Xu B, Yu JY, Xie T, Li YL, Liu MJ, Guo JX, Li HL, Yu Y, Zheng CY, Chen YH, Wang G (2018) Brassinosteroids and iron plaque affect arsenic and cadmium uptake by rice seedlings grown in hydroponic solution. Biol Plant 62:1-7. https://doi.org/10.1007/ s10535-018-0784-5

Yan Z, Chen J, Li X (2013) Methyl jasmonate as modulator of Cd toxicity in Capsicum frutescens var. fasciculatum seedlings. Ecotoxicol Environ Saf 98:203-209. https://doi.org/10.1016/j.ecoen v.2013.08.019

Yusuf M, Fariduddin Q, Hayat S, Ahmad A (2011) Nickel: an overview of uptake, essentiality and toxicity in plants. Bull Environ Contam Toxicol 86:1-17. https://doi.org/10.1007/s00128-010-0171-1

Zhu X, Chen J, Xie Z, Gao J, Ren G, Gao S, Zhou X, Kuai B (2015) Jasmonic acid promotes degreening via $\mathrm{MYC} 2 / 3 / 4-$ and ANAC019/055/072-mediated regulation of major chlorophyll catabolic genes. Plant J 84:597-610. https://doi.org/10.1111/ tpj.13030 